\title{
Asserting the climate benefits of the coal- to-gas shift across temporal and spatial scales
}

Article

Accepted Version

Tanaka, K., Cavalett, O., Collins, B. and Cherubini, F. (2019) Asserting the climate benefits of the coal-to-gas shift across temporal and spatial scales. Nature Climate Change, 9. pp. 389-396. ISSN 1758-678X doi: https://doi.org/10.1038/s41558019-0457-1 Available at https://centaur.reading.ac.uk/82879/

It is advisable to refer to the publisher's version if you intend to cite from the work. See Guidance on citing.

To link to this article DOI: http://dx.doi.org/10.1038/s41558-019-0457-1

Publisher: Nature Publishing Group

All outputs in CentAUR are protected by Intellectual Property Rights law, including copyright law. Copyright and IPR is retained by the creators or other copyright holders. Terms and conditions for use of this material are defined in the End User Agreement.

$\underline{\text { www.reading.ac.uk/centaur }}$ 
Central Archive at the University of Reading

Reading's research outputs online 
${ }^{1}$ Center for Global Environmental Research, National Institute for Environmental Studies (NIES), Tsukuba, Japan

${ }^{2}$ Institut Pierre Simon Laplace (IPSL), Centre national de la recherche scientifique (CNRS)/Sorbonne Université,

Paris, France

${ }^{3}$ Institute for Advanced Sustainability Studies (IASS), Potsdam, Germany

${ }^{4}$ Industrial Ecology Programme, Norwegian University of Science and Technology (NTNU), Trondheim, Norway

${ }^{5}$ Department of Meteorology, University of Reading, Reading, United Kingdom

* Corresponding author

17

Email:

tanaka.katsumasa@nies.go.jp

19

Phone:

+81298502493

Fax:

+81298502960 Information 


\section{Abstract}

Reducing $\mathrm{CO}_{2}$ emissions through a shift from coal to natural gas power plants is a key strategy to support pathways for climate stabilization. However, methane leakage in the natural gas supply chain and emissions of a variety of climate forcers call the net benefits of this transition into question. Here, we integrated a life cycle inventory model with multiple global and regional emission metrics and investigated the impacts of representative coal and gas power plants in China, Germany, India, and the US. We found that the coal-to-gas shift is consistent with climate stabilization objectives for the next 50 to 100 years. Our finding is robust under a range of leakage rates and uncertainties in emission data and metrics. It becomes conditional to the leakage rate in some locations only if we employ a set of metrics that essentially focuses on short-term effects. Our case for the coal-to-gas shift is stronger than previously found, reinforcing the support for coal phase-out.

\section{Main text}

Under stringent climate goals, the energy system transition to 2050 is projected to involve shifting from coal to natural gas power plants. Natural gas is considered to serve as a bridge fuel until less carbon intensive technologies, such as renewables and carbon capture and storage, become viable for large scale implementation ${ }^{1}$. Compared to coal, natural gas releases less than half the amount of $\mathrm{CO}_{2}$ upon combustion, and gas power plants are generally more efficient than coal power plants. However, natural gas is predominantly composed of $\mathrm{CH}_{4}{ }^{2}$, a potent greenhouse gas (GHG), which can leak at various stages of the supply chain ${ }^{3-13}$. Furthermore, combustion of coal and natural gas in power plants releases a different mix of short-lived climate pollutants (SLCPs) to the atmosphere (e.g. black carbon $(\mathrm{BC})$ leading to warming; $\mathrm{SO}_{\mathrm{x}}$ and organic carbon (OC) leading to cooling), whose impacts are region-dependent and sensitive to emission locations. These aspects have called into question the climatic advantage of natural gas over coal ${ }^{3,9,14-22}$.

We add a novel perspective to the coal-to-gas debate by applying recent advances in climate impact assessments, which include the multi-metric approach ${ }^{23-25}$ recommended by the United Nations Environmental Programme (UNEP) and the Society of Environmental Toxicology and Chemistry (SETAC) Life Cycle Initiative ${ }^{26}$. The multi-metric approach designates a set of emission metrics to explicitly address short-term (a few decades) and long-term (about a century) climate impacts. Our analysis considers representative power plants in some of the most important countries in terms of global power generation, i.e. China, Germany, India, and the United States 
"Asserting the climate benefits of the coal-to-gas shift across temporal and spatial scales" Katsumasa Tanaka, Otávio Cavalett, William Collins, Francesco Cherubini

Final version submitted to Nature Climate Change (1 March 2019)

52

53

54

55

(US), for which life cycle emissions of GHGs and SLCPs per unit of electricity production are derived ${ }^{27}$. We assess

the climate impacts of the coal-to-gas shift using a set of global and regional emission metrics ${ }^{28}$ and investigate the dependency of the results on $\mathrm{CH}_{4}$ leakage rates, emission and impact locations, and time scales. We show that the coal-to-gas shift reduces short- and long-term climate impacts under a broad range of $\mathrm{CH}_{4}$ leakage rates and at any emission or impact region. This conclusion is robust with respect to the uncertainties in the emission inventories and metrics assessed through a Monte Carlo analysis. However, the conclusion changes when using a set of metrics emphasizing very short-term outcomes, which is not in line with 50 to 100 -year time scales associated with climate stabilization objectives of the Paris Agreement ${ }^{29,30}$, or when using the multi-basket approach ${ }^{31-33}$, which implicitly neglects the contribution of $\mathrm{CO}_{2}$ to short-term impacts (particularly important for coal).

\section{Coal-to-gas debate}

More than three quarters of global total primary energy has been supplied by fossil fuels, including coal and natural gas, for a long period of time ${ }^{34}$. The late 1980s saw the beginning of the debate as to whether natural gas should be a mid-term bridge fuel to substitute coal temporarily along the long-term pathway for decarbonization ${ }^{35,36}$. At that time, $\mathrm{CH}_{4}$ leakage was estimated to be low. However, potentially larger leakage was already a concern ${ }^{37-39}$, leading to several studies that calculated break-even leakage rates above which the climate impacts of natural gas surpass those of coal (or oil) ${ }^{37,40,41}$. The debate was elevated to a higher level around 2010, when horizontal drilling and hydraulic fracturing (i.e. fracking) to exploit shale formations reached a substantial commercial scale in the US. It was initially claimed that these unconventional sources might have significantly higher $\mathrm{CH}_{4}$ leakage than conventional sources ${ }^{3}$ - however, subsequent studies showed otherwise, especially in the US. Nevertheless, the amount of $\mathrm{CH}_{4}$ leakage from natural gas plants, be it conventional or unconventional, remains uncertain ${ }^{3-13}$. Other environmental concerns also fuel the debate, regarding air pollution, drinking water contamination, and induced seismic activities ${ }^{42-44}$. Further considerations lie at regional and country levels $s^{45,46}$.

Previous studies on the climatic advantage of the coal-to-gas shift yield conclusions ranging from rejections $^{3,9,15}$ to conditional supports ${ }^{14,16-22}$. A key factor responsible for these diverging outcomes is the abovementioned large uncertainties in $\mathrm{CH}_{4}$ leakage. Top-down approaches using surface/aircraft/satellite 
"Asserting the climate benefits of the coal-to-gas shift across temporal and spatial scales" Katsumasa Tanaka, Otávio Cavalett, William Collins, Francesco Cherubini Final version submitted to Nature Climate Change (1 March 2019)

monitoring and atmospheric transport models tend to give higher estimates than those based on bottom-up approaches using measurements at specific facilities or for individual equipments ${ }^{47}$. The gap in estimates is partly due to difficulties in distinguishing emission sources from top-down approaches ${ }^{48,49}$ and to super-emitters ${ }^{50}$ that are under-represented in bottom-up approaches. Additional differences come from system boundaries, plant efficiencies, emission metrics, and climate forcers studied within bottom-up approaches ${ }^{18}$.

\section{Multi-metric approach}

While comprehensive insights require climate models ${ }^{15,16,19,21,41,51-53}$, climate and environmental analyses such as Life Cycle Assessment often use aggregated $\mathrm{CO}_{2}$-equivalent $\left(\mathrm{CO}_{2} \mathrm{eq}\right)$ emissions as a proxy for climate impacts ${ }^{54}$. Non- $\mathrm{CO}_{2}$ emissions can be aggregated into $\mathrm{CO}_{2}$ eq emissions on the basis of a common metric: typically the Global Warming Potential (GWP) ${ }^{55}$. GWP is defined as the ratio of the radiative forcing integrated over a given time horizon (e.g. 100 years) after the emissions of a gas of interest (e.g. $\mathrm{CH}_{4}$ ) in a unit amount (e.g. $\left.1 \mathrm{~kg}\right)$ relative to that of the reference gas of $\mathrm{CO}_{2}$. GWP was initially developed for multi-gas climate policies ${ }^{56}$, introduced to the Intergovernmental Panel on Climate Change (IPCC), and then adopted by climate policies and assessments as an accessible tool to capture total climate effects, without requiring a climate model.

This metric has, however, received critique because of the underlying scientific assumptions as well as implicit value judgements ${ }^{57}$, resulting in alternative metrics proposed ${ }^{58-63}$. A prominent alternative is the Global Temperature change Potential (GTP), in which equivalency is established with respect to the temperature change at the end of the time horizon ${ }^{60}$. The choice of radiative forcing and temperature change does not strongly affect the emission metric values ${ }^{61}$, but the difference between the integrated and end-point perspectives is more fundamental. Furthermore, emission metrics are generally sensitive to the time scale, especially for GHGs and SLCPs whose atmospheric lifetimes are substantially different from that of $\mathrm{CO}_{2}$. For example, while $\mathrm{CO}_{2}$ stays in the atmosphere on centennial or even millennium time scales ${ }^{64}, \mathrm{CH}_{4}$ mostly disappears from the atmosphere several decades after emissions ${ }^{55}$. Various stakeholders have debated whether 20 - or 100 -year time scales should be used ${ }^{65}$.

An emerging idea is to combine multiple metrics to address both short- and long-term climate impacts in parallel. However, different combining methods are proposed within the five metrics (i.e. GWP20, GWP100, GTP20, GTP50, and GTP100) available in the IPCC Fifth Assessment Report (AR5) ${ }^{55}$. On one hand, the joint use of 
"Asserting the climate benefits of the coal-to-gas shift across temporal and spatial scales" Katsumasa Tanaka, Otávio Cavalett, William Collins, Francesco Cherubini Final version submitted to Nature Climate Change (1 March 2019)

GWP100 and GTP100 was recommended through a consensus building process as part of the Life Cycle Initiative under the UNEP-SETAC flagship project ${ }^{23-26}$. GWP100 and GTP100 were assigned to capture short- and long-term climate impacts, respectively (see the discussion in Climate impact analysis). On the other hand, several previous studies adopted GWP20 and GWP100 complementarily,9,17,22,39,66, with the intent of supplementing shorter term impacts by using GWP20 in addition to GWP100 (related discussions ${ }^{9,14,19,21}$ ). That particular choice of metric combination was further proposed in a more general context ${ }^{65,67}$. In our analysis, following the UNEP-SETAC recommendations, we assess results on the basis of the complementary insights provided by GWP100 and GTP100, but also use GWP20 and GTP20 to derive additional insights.

The multi-metric approach explained above differs from the multi-basket approach ${ }^{31-33}$, which has been proposed for climate policies. While both approaches share concerns involving the single use of GWP100, the multi-basket approach circumvents this problem differently: it separates a suite of climate forcers into multiple baskets according to atmospheric lifetimes and considers multiple impacts from the baskets of climate forcers (i.e. an analogue to the scheme employed for the Montreal Protocol ${ }^{32}$ ). In contrast, the multi-metric approach does not differentiate climate forcers; rather, it applies different emission metrics to the same set of climate forcers to derive multiple impacts. For example, the multi-basket approach considers $\mathrm{CO}_{2}$ only in longterm impacts, while the multi-metric approach accounts for $\mathrm{CO}_{2}$ in both short- and long-term impacts.

\section{Climate impact analysis}

By applying GWP100 and GTP100 complementarily, we find that natural gas power plants have smaller shortand long-term impacts than coal power plants (Figure 1) under the $\mathrm{CH}_{4}$ leakage rates documented in the life cycle inventory models (see Methods). This conclusion is consistent across plant locations. Examining the impacts by stages (stage 1: extraction and transport of the fuel to the power plant; stage 2: fuel combustion at the power plant (see Methods and Supplementary Figure 1)), we find that stage 2 has larger short- and long-term impacts than stage 1 for both coal and gas (Figure 1). In terms of the contributions from individual climate forcers, the influence of $\mathrm{CO}_{2}$ is dominant in both short- and long-term impacts from coal and gas (Figure 2). If we use GWP20 or GTP20, however, the importance of $\mathrm{CO}_{2}$ is significantly reduced, with non- $\mathrm{CO}_{2}$ components like $\mathrm{SO}_{x}$ and $\mathrm{NO}_{x}$ gaining more prominence. Of note, short-term cooling impacts from $\mathrm{SO}_{\mathrm{x}}$, which has an atmospheric lifetime of just days/weeks, are most visible with GWP20. In contrast, short-term cooling impacts from $\mathrm{NO}_{\mathrm{x}}$ are most 
"Asserting the climate benefits of the coal-to-gas shift across temporal and spatial scales" Katsumasa Tanaka, Otávio Cavalett, William Collins, Francesco Cherubini Final version submitted to Nature Climate Change (1 March 2019)

evident with GTP20 because of the decadal time scales associated with the $\mathrm{CH}_{4}$ decrease in response to $\mathrm{NO}_{\mathrm{x}}$ emissions ${ }^{68}$.

We then assess the influence of larger $\mathrm{CH}_{4}$ leakage. With leakage rates varied up to $9 \%$, the benefits of the coal-to-gas shift hold with the use of GWP100 and GTP100 (Figure 3): natural gas power plants have smaller short- and long-term impacts than coal power plants. An exception are the results for China at the leakage rate of $9 \%$, in which impacts from the gas plant computed with GWP100 become almost equivalent to those from the coal plant. Results from China and India are more sensitive to the changes in $\mathrm{CH}_{4}$ leakage than those from Germany and the US, but the outcome can be reversed at the high leakage rate only in China mainly because of the higher efficiency of the representative coal plant in China than that in India (see Methods). This exceptional finding comes, however, with limited confidence, given the associated uncertainty ranges quantified by the Monte Carlo analysis (see Uncertainty analysis section in Methods). Note that emission data contribute more uncertainties than emission metrics (Supplementary Figures 2 and 3). We further tested the robustness of the results to additional factors in emission metrics, such as inclusion of climate-carbon feedbacks in metric values ${ }^{69}$, potentially larger $\mathrm{SO}_{\mathrm{x}}$ metrics accounting for effects other than the direct effects ${ }^{70}$, and higher $\mathrm{CH}_{4}$ metrics considering the effects from the shortwave forcing proposed recently ${ }^{71}$ (see Emission metrics section in Methods; Supplementary Figure 4). Our conclusions remain valid under this variety of assumptions.

However, conclusions change substantially if we look at the results with GWP20. As reported by some previous studies, short-term impacts of natural gas are less than those of coal only under certain conditions (i.e. with leakage rates below 3\%, 9\%, 5\%, and 5\% in China, Germany, the US, and India, respectively) (Figure 3). The main reason is that GWP20 emphasizes the impacts from $\mathrm{CH}_{4}$ relative to those from other climate forcers, increasing the short-term impacts of gas plants at high leakage rates. This explains the more conditional outcomes from previous studies ${ }^{14,16-22}$ using GWP20 to address the climate benefits of the coal-to-gas shift.

In general, the commonly used combination of GWP20 and GWP100 is not adequate in addressing long-term climate stabilization as called for by the Paris Agreement ${ }^{72}$. Our argument rests on the premise that it is more appropriate to consider the end point time horizon as built in the GTP concept, which is theoretically more suited for cost-effective climate stabilization in the United Nations Framework Convention on Climate Change (UNFCCC) ${ }^{73}$. Whereas the integrated time horizon in the GWP concept does not relate closely to climate stabilization, a correspondence can be made between the time horizons of GWP and GTP. GWP100 numerically 
"Asserting the climate benefits of the coal-to-gas shift across temporal and spatial scales" Katsumasa Tanaka, Otávio Cavalett, William Collins, Francesco Cherubini Final version submitted to Nature Climate Change (1 March 2019)

164

165

166

167

168

169

170

171

172

173

174

175

176

177

falls between GTP20 and GTP40, depending on the climate forcer ${ }^{74}$, which indicates that GWP100 implicitly relates temperature impacts after two to four decades. Thus, this correspondence points to a short-term emphasis inherent to GWP100. The GWP-GTP relationship further reveals that GWP20 implies very short-term climate impacts. Thus, the combined use of GWP20 and GWP100 is not consistent with the climate stabilization objectives requiring approximately 50 to 100 years to be achieved, although the choice of GWP20 and GWP100 may reflect the practical limitation that only GWP values were provided before the publication of the IPCC AR5. By comparison, we argue that the combined use of GWP100 and GTP100 jointly covers short-term (a few decades) and long-term (about a century) effects from the end-point perspective of climate stabilization. It should be noted that potential high-risk impacts (e.g. tipping points via high levels of very short-term forcing) cannot be captured by this combination of metrics, requiring GWP20 and GTP20 additionally. However, using metrics representing only short-term perspectives implicitly disregards the fundamental long-term nature of climate change mainly driven by $\mathrm{CO}_{2}$ emissions ${ }^{75}$.

An important difference was found in the assessment of short-term impacts between the multi-metric and multi-basket approaches (Supplementary Figure 5). The multi-basket approach shows substantially smaller short-term impacts from coal than the multi-metric approach. This is because the multi-basket approach does not include $\mathrm{CO}_{2}$ in short-term impacts, reducing the short-term impacts from more $\mathrm{CO}_{2}$-dominated coal plants. On the other hand, long-term impacts do not significantly differ between the two approaches. Our results highlight a crucial role of $\mathrm{CO}_{2}$ in determining short-term impacts, which is not captured by the multi-basket approach. Short-term impacts derived from the multi-basket approach cannot be interpreted as total short-term impacts if applied to climate impact assessments.

\section{Regional dimensions}

Emissions of SLCPS, which are not well-mixed in the atmosphere (excluding $\mathrm{CH}_{4}$ ), can result in regional impacts that differ from the global average and depend on regions where they are emitted ${ }^{76} . \mathrm{CH}_{4}$ itself is a well-mixed gas, but it leads to formation of $\mathrm{O}_{3}$, in the presence of precursors, which can generate spatially heterogeneous impacts $^{77}$. The GWP and GTP values used in our preceding analysis (Figures 1 to 3 ) account for emission regions but consider impacts globally, which we term as "regional-global" metrics. To disentangle regional influences, we conduct sensitivity analyses using i) "global-global" metrics, which are estimated for global emissions and global 
"Asserting the climate benefits of the coal-to-gas shift across temporal and spatial scales" Katsumasa Tanaka, Otávio Cavalett, William Collins, Francesco Cherubini Final version submitted to Nature Climate Change (1 March 2019)

impacts, and ii) "regional-regional" metrics, which are calculated for specific regions of emissions and impacts.

The global-global metrics are conceptually similar to the metrics in the IPCC (e.g. Table 8.A.1 of AR5) in terms of the assumptions for emission and impact locations. Likewise, the regional-regional metrics are similar to the Regional Temperature change Potential (RTP $)^{28,78}$. Due to data availability, the sensitivity analysis uses only GTP20 and its regional variations.

By comparing the results from regional-regional metrics with those from regional-global metrics, we illuminated the significance of accounting for impact regions. The differences were largest for the coal plants in China and India (Figure 4). In both cases, short-term impacts are largest in the latitudinal band of $90^{\circ} \mathrm{S}-28^{\circ} \mathrm{S}$ and smallest in $60^{\circ} \mathrm{N}-90^{\circ} \mathrm{N}$. The range of short-term impacts can be attributed to the impacts from $\mathrm{SO}_{x}$ and $\mathrm{NO}_{x}$ which vary across latitudinal bands (Supplementary Figures 6 to 8). Also, we show the significance of accounting for emission regions by comparing the results from global-global metrics with those from regional-global metrics. The difference was largest for the coal plant in India, which is caused by the short-term impacts from $\mathrm{NO}_{\mathrm{x}}$. Overall, we identified influences of emission and impact regions on GTP20-based impacts. However, the benefits of the coal-to-gas shift are not affected by the regional scale of the analysis, neither in terms of the emission region nor the impact area, although further analysis is required to understand regional dimensions more comprehensively.

\section{Conclusions}

The UNEP-SETAC multi-metric approach jointly using GWP100 and GTP100 shows that the coal-to-gas energy transition is consistent with climate stabilization objectives at various $\mathrm{CH}_{4}$ leakage rates and at any location considered (summarized in Table 1). This finding is different from previous findings based on GWP20 that are conditional on $\mathrm{CH}_{4}$ leakage rates. Whereas it is generally assumed that complementing GWP100 with GWP20 covers relevant time scales to assess the impacts from a variety of climate forcers, we argue that the complementary use of GWP100 and GTP100 better aligns with century-long time scales in the end-point climate stabilization perspective, while also addressing short time scales. Ways of choosing and applying metrics have a major influence on the interpretation of climate assessment outcomes, underlining the importance for a clear understanding and critical reflection on the meaning of emission metrics used, including the heterogeneities of temporal and spatial responses to different climate forcers at play. 
"Asserting the climate benefits of the coal-to-gas shift across temporal and spatial scales" Katsumasa Tanaka, Otávio Cavalett, William Collins, Francesco Cherubini Final version submitted to Nature Climate Change (1 March 2019)

coal power plants ${ }^{79-82}$. There are, however, other factors to consider for the coal-to-gas shift; for example, air quality can be evaluated together with climate impacts ${ }^{83}$, which can probably strengthen the case for the coal-togas shift. On the other hand, prioritizing the coal-to-gas shift over other mitigation measures may argue against the shift. Several studies caution about potential side-effects that an expansion of natural gas may delay the deployment of less carbon intensive technologies such as renewables, representing carbon lock-in from fossil fuel infrastructure, and thereby postponing the transition to a decarbonized society ${ }^{51-53,84-86}$. Furthermore, more detailed datasets could be considered, uncovering spatially-resolved variability associated with different components of the supply chains and trade within and across nations.

Finally, metrics are emerging as a key issue in the context of the Paris Agreement ${ }^{30,63,87}$. Current ways of applying emission metrics vary across communities. Although metrics should in principle be chosen to best meet their application purpose ${ }^{57}$, more consistency in metric usage can be useful in light of the Paris Agreement objectives and implementations. Better alignment of metric usage among scientists and decision makers can be achieved through joint engagement involving broad and interdisciplinary communities.

\section{References}

1 Edenhofer, O., R. Pichs-Madruga, Y. Sokona, S. Kadner, J.C. Minx, S. Brunner, S. Agrawala, G. Baiocchi, I.A. Bashmakov, et al. in Climate Change 2014: Mitigation of Climate Change. Contribution of Working Group III to the Fifth Assessment Report of the Intergovernmental Panel on Climate Change (ed O. Edenhofer, R. PichsMadruga, Y. Sokona, E. Farahani, S. Kadner, K. Seyboth, A. Adler, I. Baum, S. Brunner, P. Eickemeier, B. Kriemann, J. Savolainen, S. Schlömer, C. von Stechow, T. Zwickel, J.C. Minx) (Cambridge University Press, 2014).

2 Faramawy, S., Zaki, T. \& Sakr, A. A. E. Natural gas origin, composition, and processing: A review. Journal of Natural Gas Science and Engineering 34, 34-54, doi:10.1016/j.jngse.2016.06.030 (2016).

3 Howarth, R. W., Santoro, R. \& Ingraffea, A. Methane and the greenhouse-gas footprint of natural gas from shale formations. Clim. Change 106, 679, doi:10.1007/s10584-011-0061-5 (2011).

4 Cathles, L. M., Brown, L., Taam, M. \& Hunter, A. A commentary on "The greenhouse-gas footprint of natural gas in shale formations" by R.W. Howarth, R. Santoro, and Anthony Ingraffea. Clim. Change 113, 525-535, doi:10.1007/s10584-011-0333-0 (2012). 
"Asserting the climate benefits of the coal-to-gas shift across temporal and spatial scales" Katsumasa Tanaka, Otávio Cavalett, William Collins, Francesco Cherubini Final version submitted to Nature Climate Change (1 March 2019)

O'Sullivan, F. \& Paltsev, S. Shale gas production: potential versus actual greenhouse gas emissions. Environ. Res. Lett. 7, 044030, doi:10.1088/1748-9326/7/4/044030 (2012).

Weber, C. L. \& Clavin, C. Life Cycle Carbon Footprint of Shale Gas: Review of Evidence and Implications. Environ. Sci. Technol. 46, 5688-5695, doi:10.1021/es300375n (2012).

Allen, D. T. et al. Measurements of methane emissions at natural gas production sites in the United States. Proceedings of the National Academy of Sciences 110, 17768-17773, doi:10.1073/pnas.1304880110 (2013).

Brandt, A. R. et al. Methane Leaks from North American Natural Gas Systems. Science 343, 733-735, doi:10.1126/science.1247045 (2014).

Howarth, R. W. A bridge to nowhere: methane emissions and the greenhouse gas footprint of natural gas. Energy Science \& Engineering 2, 47-60, doi:10.1002/ese3.35 (2014).

Cremonese, L. \& Gusev, A. The Uncertain Climate Cost of Natural Gas: Assessment of methane leakage discrepancies in Europe, Russia and the US, and implications for sustainability. (Institute for Advanced Sustainability Studies, Potsdam, Germany, 2016).

Balcombe, P., Anderson, K., Speirs, J., Brandon, N. \& Hawkes, A. The Natural Gas Supply Chain: The Importance of Methane and Carbon Dioxide Emissions. ACS Sustainable Chemistry \& Engineering 5, 3-20, doi:10.1021/acssuschemeng.6b00144 (2017).

International Energy Agency. World Energy Outlook 2017. 763 (2017).

Alvarez, R. A. et al. Assessment of methane emissions from the U.S. oil and gas supply chain. Science 361, 186188, doi:10.1126/science.aar7204 (2018).

4 Hultman, N., Rebois, D., Scholten, M. \& Ramig, C. The greenhouse impact of unconventional gas for electricity generation. Environ. Res. Lett. 6, 044008, doi:10.1088/1748-9326/6/4/044008 (2011).

Wigley, T. M. L. Coal to gas: the influence of methane leakage. Clim. Change 108, 601, doi:10.1007/s10584011-0217-3 (2011).

Alvarez, R. A., Pacala, S. W., Winebrake, J. J., Chameides, W. L. \& Hamburg, S. P. Greater focus needed on methane leakage from natural gas infrastructure. Proceedings of the National Academy of Sciences 109, 64356440, doi:10.1073/pnas.1202407109 (2012).

Burnham, A. et al. Life-Cycle Greenhouse Gas Emissions of Shale Gas, Natural Gas, Coal, and Petroleum. Environ. Sci. Technol. 46, 619-627, doi:10.1021/es201942m (2012).

Heath, G. A., O’Donoughue, P., Arent, D. J. \& Bazilian, M. Harmonization of initial estimates of shale gas life cycle greenhouse gas emissions for electric power generation. Proceedings of the National Academy of 
"Asserting the climate benefits of the coal-to-gas shift across temporal and spatial scales" Katsumasa Tanaka, Otávio Cavalett, William Collins, Francesco Cherubini Final version submitted to Nature Climate Change (1 March 2019)

21

Sciences 111, E3167-E3176, doi:10.1073/pnas.1309334111 (2014).

Zhang, X., Myhrvold, N. P. \& Caldeira, K. Key factors for assessing climate benefits of natural gas versus coal electricity generation. Environ. Res. Lett. 9, 114022 (2014).

Lueken, R., Klima, K., Griffin, W. M. \& Apt, J. The climate and health effects of a USA switch from coal to gas electricity generation. Energy 109, 1160-1166, doi:10.1016/j.energy.2016.03.078 (2016). Farquharson, D. et al. Beyond Global Warming Potential: A Comparative Application of Climate Impact Metrics for the Life Cycle Assessment of Coal and Natural Gas Based Electricity. Journal of Industrial Ecology 21, 857873, doi:10.1111/jiec.12475 (2017).

22 Qin, Y., Edwards, R., Tong, F. \& Mauzerall, D. L. Can Switching from Coal to Shale Gas Bring Net Carbon Reductions to China? Environ. Sci. Technol. 51, 2554-2562, doi:10.1021/acs.est.6b04072 (2017).

Cherubini, F. et al. Bridging the gap between impact assessment methods and climate science. Environmental Science \& Policy 64, 129-140, doi:10.1016/j.envsci.2016.06.019 (2016). Levasseur, A. et al. Enhancing life cycle impact assessment from climate science: Review of recent findings and recommendations for application to LCA. Ecol. Indicators 71, 163-174, doi:10.1016/j.ecolind.2016.06.049 (2016). Levasseur, A. et al. in Global Guidance for Life Cycle Impact Assessment Indicators Vol. 1 (eds R. Frischknecht \& O. Jolliet) Ch. 3, 59-75 (UNEP, 2016). Jolliet, O. et al. Global guidance on environmental life cycle impact assessment indicators: impacts of climate change, fine particulate matter formation, water consumption and land use. The International Journal of Life Cycle Assessment, doi:10.1007/s11367-018-1443-y (2018).

27 Wernet, G. et al. The ecoinvent database version 3 (part I): overview and methodology. The International Journal of Life Cycle Assessment 21, 1218-1230, doi:10.1007/s11367-016-1087-8 (2016).

Collins, W. J. et al. Global and regional temperature-change potentials for near-term climate forcers. Atmos. Chem. Phys. 13, 2471-2485, doi:10.5194/acp-13-2471-2013 (2013).

29 Geden, O. \& Löschel, A. Define limits for temperature overshoot targets. Nature Geoscience 10, 881-882, doi:10.1038/s41561-017-0026-z (2017).

Tanaka, K. \& O'Neill, B. C. Paris Agreement zero emissions goal is not always consistent with $2^{\circ} \mathrm{C}$ and $1.5^{\circ} \mathrm{C}$ temperature targets. Nature Climate Change 8, 319-324, doi:10.1038/s41558-018-0097-x (2018).

Jackson, S. C. Parallel Pursuit of Near-Term and Long-Term Climate Mitigation. Science 326, 526-527, doi:10.1126/science.1177042 (2009). 
"Asserting the climate benefits of the coal-to-gas shift across temporal and spatial scales" Katsumasa Tanaka, Otávio Cavalett, William Collins, Francesco Cherubini Final version submitted to Nature Climate Change (1 March 2019)

Daniel, J. et al. Limitations of single-basket trading: lessons from the Montreal Protocol for climate policy. Clim. Change 111, 241-248, doi:10.1007/s10584-011-0136-3 (2012).

Smith, S. M. et al. Equivalence of greenhouse-gas emissions for peak temperature limits. Nature Clim. Change 2, 535-538, doi:org/10.1038/nclimate1496 (2012).

34 Court, V. \& Fizaine, F. Long-Term Estimates of the Energy-Return-on-Investment (EROI) of Coal, Oil, and Gas Global Productions. Ecol. Econ. 138, 145-159, doi:10.1016/j.ecolecon.2017.03.015 (2017). US EPA. Policy Options for Stabilizing Global Climate. Report to Congress: Main Report. 573 (1990).

Lelieveld, J. \& Crutzen, P. J. Indirect chemical effects of methane on climate warming. Nature 355, 339-342, doi:10.1038/355339a0 (1992).

Lelieveld, J., Crutzen, P. J. \& Brühl, C. Climate effects of atmospheric methane. Chemosphere 26, 739-768, doi:10.1016/0045-6535(93)90458-H (1993).

Reshetnikov, A. I., Paramonova, N. N. \& Shashkov, A. A. An evaluation of historical methane emissions from the Soviet gas industry. Journal of Geophysical Research: Atmospheres 105, 3517-3529, doi:10.1029/1999JD900761 (2000).

Lelieveld, J. et al. Greenhouse gases: Low methane leakage from gas pipelines. Nature 434, 841-842, doi:10.1038/434841a (2005).

Rodhe, H. A Comparison of the Contribution of Various Gases to the Greenhouse Effect. Science 248, 12171219, doi:10.1126/science.248.4960.1217 (1990).

Hayhoe, K., Kheshgi, H. S., Jain, A. K. \& Wuebbles, D. J. Substitution of Natural Gas for Coal: Climatic Effects of Utility Sector Emissions. Clim. Change 54, 107-139, doi:10.1023/a:1015737505552 (2002).

Jackson, R. B. et al. The Environmental Costs and Benefits of Fracking. Annual Review of Environment and Resources 39, 327-362, doi:10.1146/annurev-environ-031113-144051 (2014).

Vengosh, A., Jackson, R. B., Warner, N., Darrah, T. H. \& Kondash, A. A Critical Review of the Risks to Water Resources from Unconventional Shale Gas Development and Hydraulic Fracturing in the United States. Environ. Sci. Technol. 48, 8334-8348, doi:10.1021/es405118y (2014).

Weingarten, M., Ge, S., Godt, J. W., Bekins, B. A. \& Rubinstein, J. L. High-rate injection is associated with the increase in U.S. mid-continent seismicity. Science 348, 1336-1340, doi:10.1126/science.aab1345 (2015). Industry B 3, 12-26, doi:10.1016/j.ngib.2016.02.002 (2016). 
"Asserting the climate benefits of the coal-to-gas shift across temporal and spatial scales" Katsumasa Tanaka, Otávio Cavalett, William Collins, Francesco Cherubini Final version submitted to Nature Climate Change (1 March 2019)

Nature Energy 3, 365-372, doi:10.1038/s41560-018-0109-0 (2018).

Zavala-Araiza, D. et al. Reconciling divergent estimates of oil and gas methane emissions. Proceedings of the National Academy of Sciences 112, 15597-15602, doi:10.1073/pnas.1522126112 (2015).

Miller, S. M. et al. Anthropogenic emissions of methane in the United States. Proceedings of the National Academy of Sciences 110, 20018-20022, doi:10.1073/pnas.1314392110 (2013).

49 Caulton, D. R. et al. Toward a better understanding and quantification of methane emissions from shale gas development. Proceedings of the National Academy of Sciences 111, 6237-6242, doi:10.1073/pnas.1316546111 (2014).

Zavala-Araiza, D. et al. Super-emitters in natural gas infrastructure are caused by abnormal process conditions. Nature Communications 8, 14012, doi:10.1038/ncomms14012 (2017).

51 Levi, M. Climate consequences of natural gas as a bridge fuel. Clim. Change 118, 609-623, doi:10.1007/s10584-012-0658-3 (2013).

McJeon, H. et al. Limited impact on decadal-scale climate change from increased use of natural gas. Nature 514, 482-485, doi:10.1038/nature13837 (2014).

Hausfather, Z. Bounding the climate viability of natural gas as a bridge fuel to displace coal. Energy Policy 86, 286-294, doi:10.1016/j.enpol.2015.07.012 (2015).

Hellweg, S. \& Milà i Canals, L. Emerging approaches, challenges and opportunities in life cycle assessment. Science 344, 1109-1113, doi:10.1126/science.1248361 (2014).

Myhre, G. et al. in Climate Change 2013: The Physical Science Basis. Contribution of WGI to the IPCC AR5 (eds T.F. Stocker et al.) Ch. 8, 659-740 (Cambridge University Press, 2013).

Lashof, D. A. \& Ahuja, D. R. Relative contributions of greenhouse gas emissions to global warming. Nature 344, 529-531, doi:10.1038/344529a0 (1990).

Tanaka, K., Peters, G. P. \& Fuglestvedt, J. S. Policy Update: Multicomponent climate policy: why do emission metrics matter? Carbon Management 1, 191-197, doi:10.4155/cmt.10.28 (2010).

Kandlikar, M. Indices for comparing greenhouse gas emissions: integrating science and economics. Energy Economics 18, 265-281, doi:10.1016/S0140-9883(96)00021-7 (1996).

Manne, A. S. \& Richels, R. G. An alternative approach to establishing trade-offs among greenhouse gases. Nature 410, 675-677, doi:10.1038/35070541 (2001). comparing climate impacts of emissions of greenhouse gases. Clim. Change 68, 281-302, doi:10.1007/s10584- 
"Asserting the climate benefits of the coal-to-gas shift across temporal and spatial scales" Katsumasa Tanaka, Otávio Cavalett, William Collins, Francesco Cherubini Final version submitted to Nature Climate Change (1 March 2019)

005-1146-9 (2005).

61 Tanaka, K., O’Neill, B. C., Rokityanskiy, D., Obersteiner, M. \& Tol, R. Evaluating Global Warming Potentials with historical temperature. Clim. Change 96, 443-466, doi:10.1007/s10584-009-9566-6 (2009). (iGTP) and relationships between emission metrics. Environ. Res. Lett. 6, 044021, doi:10.1088/17489326/6/4/044021 (2011).

Allen, M. R. et al. A solution to the misrepresentations of CO2-equivalent emissions of short-lived climate pollutants under ambitious mitigation. npj Climate and Atmospheric Science 1, 16, doi:10.1038/s41612-0180026-8 (2018). Joos, F. et al. Carbon dioxide and climate impulse response functions for the computation of greenhouse gas metrics: a multi-model analysis. Atmospheric Chemistry and Physics 13, 2793-2825, doi:10.5194/acp-13-27932013 (2013).

Ocko, I. B. et al. Unmask temporal trade-offs in climate policy debates. Science 356, 492-493, doi:10.1126/science.aaj2350 (2017).

Abrahams, L. S., Samaras, C., Griffin, W. M. \& Matthews, H. S. Life Cycle Greenhouse Gas Emissions From U.S. Liquefied Natural Gas Exports: Implications for End Uses. Environ. Sci. Technol. 49, 3237-3245, doi:10.1021/es505617p (2015).

Fesenfeld, L. P., Schmidt, T. S. \& Schrode, A. Climate policy for short- and long-lived pollutants. Nature Climate Change 8, 933-936, doi:10.1038/s41558-018-0328-1 (2018).

Wild, O., Prather, M. J. \& Akimoto, H. Indirect long-term global radiative cooling from NOx Emissions. Geophys. Res. Lett. 28, 1719-1722, doi:10.1029/2000GL012573 (2001).

69 Gasser, T. et al. Accounting for the climate-carbon feedback in emission metrics. Earth Syst. Dynam. 8, 235253, doi:10.5194/esd-8-235-2017 (2017).

Aamaas, B., Berntsen, T. K., Fuglestvedt, J. S., Shine, K. P. \& Collins, W. J. Regional temperature change potentials for short-lived climate forcers based on radiative forcing from multiple models. Atmos. Chem. Phys. 17, 10795-10809, doi:10.5194/acp-17-10795-2017 (2017).

Etminan, M., Myhre, G., Highwood, E. J. \& Shine, K. P. Radiative forcing of carbon dioxide, methane, and nitrous oxide: A significant revision of the methane radiative forcing. Geophys. Res. Lett. 43, 12,614-612,623, doi:10.1002/2016GL071930 (2016). 
"Asserting the climate benefits of the coal-to-gas shift across temporal and spatial scales" Katsumasa Tanaka, Otávio Cavalett, William Collins, Francesco Cherubini Final version submitted to Nature Climate Change (1 March 2019) Science eLetter, http://science.sciencemag.org/content/356/6337/492/tab-e-letters (2017).

$400 \quad 73$

401

402

$403 \quad 74$

404

$405 \quad 75$

406

407

$408 \quad 76$

409

410

Tol, R. S. J., Berntsen, T. K., O’Neill, B. C., Fuglestvedt, J. S. \& Shine, K. P. A unifying framework for metrics for aggregating the climate effect of different emissions. Environ. Res. Lett. 7, 044006, doi:10.1088/17489326/7/4/044006 (2012).

4 Allen, M. R. et al. New use of global warming potentials to compare cumulative and short-lived climate pollutants. Nature Clim. Change 6, 773-776, doi:10.1038/nclimate2998 (2016).

Balcombe, P., Speirs, J. F., Brandon, N. P. \& Hawkes, A. D. Methane emissions: choosing the right climate metric and time horizon. Environmental Science: Processes \& Impacts 20, 1323-1339, doi:10.1039/C8EM00414E (2018).

76 Lund, M. T., Berntsen, T., Fuglestvedt, J. S., Ponater, M. \& Shine, K. P. How much information is lost by using global-mean climate metrics? an example using the transport sector. Clim. Change 113, 949-963, doi:10.1007/s10584-011-0391-3 (2012).

Fiore, A. M. et al. Linking ozone pollution and climate change: The case for controlling methane. Geophys. Res. Lett. 29, 1919, doi:10.1029/2002GL015601 (2002).

78 Shindell, D. \& Faluvegi, G. Climate response to regional radiative forcing during the twentieth century. Nature Geosci 2, 294-300, doi:10.1038/ngeo473 (2009).

Johnson, N. et al. Stranded on a low-carbon planet: Implications of climate policy for the phase-out of coalbased power plants. Technol. Forecast. Soc. Change 90, 89-102, doi:10.1016/j.techfore.2014.02.028 (2015).

80 Pfeiffer, A., Millar, R., Hepburn, C. \& Beinhocker, E. The ' $2{ }^{\circ} \mathrm{C}$ capital stock' for electricity generation: Committed cumulative carbon emissions from the electricity generation sector and the transition to a green economy. Applied Energy 179, 1395-1408, doi:10.1016/j.apenergy.2016.02.093 (2016).

81 Edenhofer, O., Steckel, J. C., Jakob, M. \& Bertram, C. Reports of coal's terminal decline may be exaggerated. Environ. Res. Lett. 13, 024019, doi:10.1088/1748-9326/aaa3a2 (2018).

82 Spencer, T. et al. The $1.5^{\circ} \mathrm{C}$ target and coal sector transition: at the limits of societal feasibility. Climate Policy 18, 335-351, doi:10.1080/14693062.2017.1386540 (2018).

Schmale, J., Shindell, D., von Schneidemesser, E., Chabay, I. \& Lawrence, M. Air pollution: Clean up our skies. Nature 515, 335-337, doi:10.1038/515335a (2014). Schrag, D. P. Is Shale Gas Good for Climate Change? Daedalus 141, 72-80, doi:10.1162/DAED_a_00147 (2012). Newell, R. G. \& Raimi, D. Implications of Shale Gas Development for Climate Change. Environ. Sci. Technol. 48, 8360-8368, doi:10.1021/es4046154 (2014). 
"Asserting the climate benefits of the coal-to-gas shift across temporal and spatial scales" Katsumasa Tanaka, Otávio Cavalett, William Collins, Francesco Cherubini Final version submitted to Nature Climate Change (1 March 2019)

Zhang, X., Myhrvold, N. P., Hausfather, Z. \& Caldeira, K. Climate benefits of natural gas as a bridge fuel and

430

potential delay of near-zero energy systems. Applied Energy 167, 317-322, doi:10.1016/j.apenergy.2015.10.016 (2016).

Fuglestvedt, J. et al. Implications of possible interpretations of 'greenhouse gas balance' in the Paris Agreement. Phil. Trans. R. Soc. A. 376, doi:10.1098/rsta.2016.0445 (2018).

\section{Methods}

\section{$\underline{\text { Overview of emission data }}$}

Life cycle emissions of GHGs and SLCPs from coal and natural gas power plants are produced using the ecoinvent database version $3.4^{27,88,89}$ (Supplementary Table 1). We chose representative power plants in China, Germany, the US, and India and mapped direct and indirect emissions along the full supply chain and during power plant operation. A process flow diagram of the value chains for coal and gas plants is provided in Supplementary Figure 1, highlighting main stages and emission sources. Life cycle emissions are aggregated in two major stages.

- Stage 1: direct and indirect emissions to deliver the fuel to the power plant, including mining, extraction, processing, compression, storage, and transport systems

- Stage 2: fuel combustion at the power plant and minor emissions due to the production and supply of the commodities and chemicals used to run the power plant and disposal of combustion ashes to landfill

Power plants are representative of averaged conditions for specific technologies, conversion efficiencies, fuels, and emission factors in the respective countries. The database provides emission inventories for coal and gas plants in 31 sub-regions in China, 13 in India, seven in the US and one in Germany. We compute the average figures considering all sub-regions in each country. Further details in the power plants are found in Coal and natural gas power plants section. Uncertainties in emission factors and variabilities of power plant efficiencies are shown in Supplementary Tables 2 and 3, respectively, and are the basis for the Monte Carlo analysis (see Uncertainty analysis section).

A suite of components including SLCPs is considered in our analysis. Emissions of $\mathrm{CO}_{2}, \mathrm{CH}_{4}, \mathrm{~N}_{2} \mathrm{O}, \mathrm{CO}$, $\mathrm{NO}_{\mathrm{x}}, \mathrm{VOC}$, and $\mathrm{SO}_{\mathrm{x}}$ are directly derived from the ecoinvent database. $\mathrm{CH}_{4}$ emissions are varied in our analysis in terms of leakage rates up to $9 \%$ (see $\mathrm{CH}_{4}$ leakage section). For $\mathrm{BC}$ and $\mathrm{OC}$ emissions, we complemented the database with related estimates gathered from the literature since ecoinvent only reports the emissions of particular matter (PM) (see BC and OC emissions section). 
"Asserting the climate benefits of the coal-to-gas shift across temporal and spatial scales" Katsumasa Tanaka, Otávio Cavalett, William Collins, Francesco Cherubini Final version submitted to Nature Climate Change (1 March 2019)

In line with the Life Cycle Assessment methodology, our study assumes that all emissions occur

459

460

461

462

463

464

465

466

467

468

instantaneously; we analyze pulse emissions without accounting for their temporal distribution given by plant lifetimes or the periods of plant operations. An inclusion of temporally distributed emissions would offer more realistic insights; however, emission metrics we employed are based on fixed time horizons (e.g. 100 years) and are not directly designed to deal with sustained emissions occurring at different points in time ${ }^{60}$, although it is possible to apply related interpretations ${ }^{90,91}$.

\section{Coal and natural gas power plants}

Electricity from coal is produced from average hard coal power plants (ecoinvent activity name: "electricity production, hard coal"). Hard coal includes anthracite, coking coal, and other bituminous coal. Average hard coal requirements per unit of electricity produced are $0.493 \mathrm{~kg} / \mathrm{kWh}$ in China, $0.402 \mathrm{~kg} / \mathrm{kWh}$ in Germany, 0.458 $\mathrm{kg} / \mathrm{kWh}$ in the US, and $0.733 \mathrm{~kg} / \mathrm{kWh}$ in India. Hard coal supply considers underground coal mines in the respective countries, except for India, whose coals are imported from the average global market. Hard coal emission inventories include all emissions from mining processes to extract coal from the ground and all the associated upstream emissions from inputs, infrastructure, and energy requirements for mine construction and operation, coal preparation, and gas leakage as well as the country-specific transportation systems. Coal energy content is $22.8 \mathrm{MJ} / \mathrm{kg}$ China, $24.0 \mathrm{MJ} / \mathrm{kg}$ in Germany, $24.8 \mathrm{MJ} / \mathrm{kg}$ in the US, and $19.3 \mathrm{MJ} / \mathrm{kg} \mathrm{in} \mathrm{India}{ }^{88}$ (Supplementary Table 3). Additional details on the selected processes and sources for emissions are available in refs. $^{27,88,89}$.

Electricity from natural gas is produced from combined cycle power plants, without associated heat cogeneration (ecoinvent activity name: "electricity production, natural gas, combined cycle power plant"). Average natural gas requirements per unit of electricity produced are $0.289 \mathrm{~m}^{3} / \mathrm{kWh}$ in China, $0.164 \mathrm{~m}^{3} / \mathrm{kWh}$ in Germany, $0.170 \mathrm{~m}^{3} / \mathrm{kWh}$ in the US, and $0.287 \mathrm{~m}^{3} / \mathrm{kWh}$ in India. Natural gas market in Germany accounts for internal production on dedicated onshore gas fields (8\%), in addition to imports from the Netherlands (21\%), Norway (32\%), and Russia (38\%). Natural gas market in the US accounts for internal production in dedicated onshore gas fields (70\%) and on-shore combined oil and gas production (30\%). The natural gas availability in China and India considers the supply from the average global market of natural gas, which includes imports (3\%) from several countries (e.g. Nigeria, Germany, Algeria, the Netherlands, Norway, and Russia), production in dedicated onshore 
"Asserting the climate benefits of the coal-to-gas shift across temporal and spatial scales" Katsumasa Tanaka, Otávio Cavalett, William Collins, Francesco Cherubini Final version submitted to Nature Climate Change (1 March 2019) gas fields (56\%), both on- and off-shore combined production of oil and gas (29\%), and liquefied natural gas

(LNG) (12\%). Emission inventories include materials, infrastructure and energy requirements for gas field construction and operation, natural gas processing, sweetening, drying, and all upstream activities as well as gas leakage. Natural gas energy content is $39 \mathrm{MJ} / \mathrm{m}^{3}$ in all four countries ${ }^{88}$ (Supplementary Table 3). In the case of LNG, impacts related to liquefaction, storage, shipping, and regasification are also included in the emission inventories. Energy requirements for compressor stations and gas leakage as well as the construction and operation of pipeline infrastructure for transport of natural gas are specifically considered for different countries. Furthermore, we assess the emissions from liquefaction and regasification associated with LNG. Emission inventories from natural gas and LNG power plants are compared in Supplementary Table 4 (stage 1 only). In the ecoinvent database, the LNG supply for the plant in Germany is from Algeria, while the plants in China, the US, and India rely on the LNG supply from Middle East and the rest of the world. Consequently, emissions from the LNG plant in Germany are considerably smaller than those in the other locations. However, the difference in the climate impacts between natural gas and LNG plants (Supplementary Figure 9) is not substantial because emissions from stage 2 are more important in magnitude than those from stage 1 , confirming the small contribution of liquefaction and regasification to the total value chain impacts ${ }^{66}$.

\section{$\underline{\mathrm{BC} \text { and } \mathrm{OC} \text { emissions }}$}

Emission factors for $\mathrm{BC}$ and $\mathrm{OC}$ are calculated using different approaches for stage 1 (and auxiliary processes in stage 2) and the rest of stage 2 (i.e. direct emissions from fuel combustion at the plant). BC and OC emissions from the former are based on the amount of life cycle emissions of PM lower than $10 \mu m^{92}$. Emissions from the latter are quantified using plant-specific emission factors. For China and India, BC and OC emissions from the coal plants are $0.077 \mathrm{~g} / \mathrm{kg}_{\text {coal }}$ and $0.254 \mathrm{~g} / \mathrm{kg}_{\text {coal, }}$ respectively, and OC emissions from the gas plants are $0.015 \mathrm{~g} / \mathrm{kg}_{\text {gas }}$ (where no BC emissions occur) ${ }^{93}$. For Germany and the US, BC and OC emission factors from the coal plants are $0.029 \mathrm{~g} / \mathrm{kg}_{\text {coal }}$ and $0.015 \mathrm{~g} / \mathrm{kg}_{\text {coal, }}$ respectively, and those from the gas plants are $0.0084 \mathrm{~g} / \mathrm{kg}_{\text {gas }}$ and $0.092 \mathrm{~g} / \mathrm{kg}_{\text {gas }}$ respectively ${ }^{94,95}$

\section{$\underline{\mathrm{CH}}_{4}$ leakage}

We define $\mathrm{CH}_{4}$ leakage as the total $\mathrm{CH}_{4}$ emissions from the natural gas supply chain, including unintended 
"Asserting the climate benefits of the coal-to-gas shift across temporal and spatial scales" Katsumasa Tanaka, Otávio Cavalett, William Collins, Francesco Cherubini Final version submitted to Nature Climate Change (1 March 2019)

514

515

516

517

518

519

520

521

522

523

524

525

526

527

fugitive releases and intended vented releases, although the definition varies across literature ${ }^{12}$. It is widely recognized that $\mathrm{CH}_{4}$ leakage rates are uncertain ${ }^{3-13}$. Our analysis uses a range of leakage rates that cover most of reported values. We do not analyze extremely high leakage rates (i.e. super-emitters ${ }^{50}$ ) since we deal with representative or "average" power plants of four different countries. The 2017 World Energy Outlook from the International Energy Agency reports a global average leakage rate of $1.7 \%{ }^{12}$. A recent synthesis work gives a leakage estimate of $2.3 \%$ for the US (95\% confidence interval of $2.0-2.7 \%)^{13} \cdot \mathrm{CH}_{4}$ measurements and inventory data are concentrated in the US, leaving the leakage estimates in the other parts of the world more uncertain. Leakage rates outside of the US could be high due to less regulatory oversights on environmental issues among other factors.

The $\mathrm{CH}_{4}$ leakage rates directly obtained from the ecoinvent database are approximately $1 \%$ (i.e. $0.62 \%$, $0.79 \%, 1.23 \%$, and $0.62 \%$ in China, Germany, the US, and India, respectively). Due to the alternative references used in the ecoinvent database, these figures are lower than average estimates introduced above. In the analysis, we vary the leakage rate up to $9 \%$ at each plant location to cover most leakage estimates in the literature ${ }^{66}$. Climate impacts are computed for leakage rates from $2 \%$ up to $9 \%$, with $1 \%$ progressive increment. Emissions of other gases may also be larger under higher $\mathrm{CH}_{4}$ leakage (e.g. venting releases) - however, we keep other emissions constant in varying the leakage rate due to the scarcity of data and single out the $\mathrm{CH}_{4}$ leakage effect.

\section{$\underline{\text { Emission metrics }}$}

Metric values are based on a previous study ${ }^{28}$ that used radiative forcing calculations from the Task Force on Hemispheric Transport of Air Pollution Source-Receptor global chemical transport models ${ }^{96,97}$, except for $\mathrm{N}_{2} \mathrm{O}$ metric values directly adopted from the IPCC AR5 (Supplementary Tables 5 and 6). Uncertainties in emission metrics considered in this study represent the spreads of model responses to the emissions of SLCPs. Uncertainties associated with the responses to the emissions of long-lived gases $\left(\mathrm{CO}_{2}\right.$ and $\left.\mathrm{N}_{2} \mathrm{O}\right)$ are reported ${ }^{64,98}$ but not included in our analysis. The $\mathrm{CH}_{4}$ metric values are scaled to be consistent with the corresponding AR5 values, that is, the long-term ozone contribution is increased to $50 \%$ of the $\mathrm{CH}_{4}$-only part. We further modified the values of all $\mathrm{CH}_{4}$ metric (including RTP20) to account for the $\mathrm{CO}_{2}$ production from $\mathrm{CH}_{4}$ oxidation ${ }^{99}$. The $\mathrm{CH}_{4}$ metrics used here thus correspond to those for " $\mathrm{CH}_{4}$ of fossil origin" in Table 8.A.1 of the IPCC AR5, although the values are slightly different. The metric values used here are contingent on various assumptions. Below we 
"Asserting the climate benefits of the coal-to-gas shift across temporal and spatial scales" Katsumasa Tanaka, Otávio Cavalett, William Collins, Francesco Cherubini Final version submitted to Nature Climate Change (1 March 2019)

discuss three main underlying assumptions and their implications to the results.

First, metric values used in our analysis do not fully account for climate-carbon feedbacks ${ }^{100}$. Like the standard approach in Table 8.A.1 of the IPCC AR5, climate-carbon feedbacks are included only in the denominators of metrics (i.e. the $\mathrm{CO}_{2}$ emission parts). We provide an alternative set of metric values fully accounting for climate-carbon feedbacks (i.e. both in the denominators and numerators of metrics) in Supplementary Tables 7 and 8, which corresponds to Table 8.SM.15 of AR5. We calculated these metric values by combining the outcomes of previous studies ${ }^{28,69}$. Note that it was recently reported that AR5 metric values fully accounting for climate-carbon feedbacks need downward correction because of the treatment of the additional $\mathrm{CO}_{2}$ released from climate-carbon feedbacks in the metric numerators ${ }^{69}$. Our metric calculations are based on the corrected approach. With the use of metric values fully including climate-carbon feedbacks, the short-term climate benefits of the coal-to-gas shift (based on GWP100) become slightly marginalized (Supplementary Figure 4b). But such changes are not large enough to affect the overall results summarized in Table 1.

Second, our metric calculation approach accounts for only the direct effects of aerosols. Recent studies have attempted to incorporate indirect effects, semi-direct effects, and snow-albedo effects ${ }^{70}$, but values are available only for two emission regions. The $\mathrm{SO}_{\mathrm{x}}$ metric values from these studies are approximately twice larger than those used here. Assuming that the values of all $\mathrm{SO}_{\mathrm{x}}$ metrics accounting for other effects are twice as large as those used in our analysis, the short-term climate benefits of the coal-to-gas shift could be significantly reduced (Supplementary Figure 4c). The break-even leakage rate of the short-term impacts in China might shift from $9 \%$ to $6 \%$, even though this emerges only under a speculative assumption.

Third, a revision of GWP100 for $\mathrm{CH}_{4}$ (i.e. 32), approximately $14 \%$ higher than the AR5 estimate of 28, was proposed recently ${ }^{71}$. This upward revision is due to the shortwave forcing that were not considered in previous radiative transfer calculations. This upward adjustment can decrease the gain in the short-term climate impacts from the coal-to-gas shift (Supplementary Figure 4d) but does not affect the overall outcome in Table 1.

$\underline{\text { Uncertainty analysis }}$

The Monte Carlo analysis considers two major strands of uncertainties, those in emission data and those in emission metrics. Emission data have two further sources of uncertainties: emission factors and plant efficiencies. First, uncertainties in emission factors are derived from six semi-quantitative indices describing 
"Asserting the climate benefits of the coal-to-gas shift across temporal and spatial scales" Katsumasa Tanaka, Otávio Cavalett, William Collins, Francesco Cherubini Final version submitted to Nature Climate Change (1 March 2019)

570

571

572

573

574

575

576

reliability, completeness, temporal correlation, geographical correlation, technology, and a factor related to the intrinsic measurement uncertainty. Second, uncertainties in plant efficiencies are the variabilities of efficiencies from all power plants with the same technology in different sub-regions of each country (Supplementary Table 3). Then, the six uncertainty aspects of emission factors and the variabilities of plant efficiencies are combined to yield the uncertainties in emission data considered in our analysis (Supplementary Table 2). Uncertainties in emission metrics represent the diverse nature of models used to calculate emission metrics (see Emission metrics section; Supplementary Table 6) $)^{28,96,97}$. A triangular distribution is assumed for each uncertain parameter. In the Monte Carlo analysis, we repeated 10,000 model runs by randomly selecting values for a total of 16 parameters, which consist of nine parameters for emission data (of nine GHGs and SLCPS) and seven parameters for emission metrics (of seven SLCPS), for each country, fuel type, and emission metric.

\section{$\underline{\text { Impact units }}$}

Our analysis reports short- and long-term climate impacts in $\mathrm{gCH}_{4} \mathrm{eq} / \mathrm{kWh}$ and $\mathrm{gCO}_{2} \mathrm{eq} / \mathrm{kWh}$, respectively ${ }^{101}$. We deliberately differentiate the units to avoid confusion between different types of impacts, but different units do not affect our conclusions. $\mathrm{CH}_{4} \mathrm{eq}$ emissions can be obtained by dividing $\mathrm{CO}_{2}$ eq emissions by associated $\mathrm{CH}_{4}$ eq metric values. In other words, converting $\mathrm{CO}_{2}$ eq-based results to $\mathrm{CH}_{4}$ eq-based results requires only linear scaling. The use of different unit influences the absolute outcomes but does not alter the relative importance of gases and pollutants in climate impacts, thus having no effect on the conclusions of this study.

\section{$\underline{\text { Data availability }}$}

The data that support the findings of this study are available from the corresponding author upon request.

\section{$\underline{\text { Code availability }}$}

The computer codes used to generate results presented in this study are available from the corresponding author upon request.

\section{References (Methods)}

88 Dones, R. et al. Life Cycle Inventories of Energy Systems: Results for Current Systems in Switzerland and other 
"Asserting the climate benefits of the coal-to-gas shift across temporal and spatial scales" Katsumasa Tanaka, Otávio Cavalett, William Collins, Francesco Cherubini Final version submitted to Nature Climate Change (1 March 2019)

UCTE Countries. Final report ecoinvent data v2.0, No. 5. (Swiss Centre for Life Cycle Inventories, Dübendorf, Switzerland, 2007).

89

Moreno Ruiz, E. et al. Documentation of changes implemented in the ecoinvent database v3.4 ecoinvent. (Zürich, Switzerland, 2017).

Boucher, O. \& Reddy, M. S. Climate trade-off between black carbon and carbon dioxide emissions. Energy Policy 36, 193-200, doi:10.1016/j.enpol.2007.08.039 (2008).

Azar, C. \& Johansson, D. J. A. On the relationship between metrics to compare greenhouse gases - the case of IGTP, GWP and SGTP. Earth Syst. Dynam. 3, 139-147, doi:10.5194/esd-3-139-2012 (2012).

Bond, T. C. et al. Bounding the role of black carbon in the climate system: A scientific assessment. Journal of Geophysical Research: Atmospheres 118, 5380-5552, doi:10.1002/jgrd.50171 (2013).

Reddy, M. S. \& Venkataraman, C. Inventory of aerosol and sulphur dioxide emissions from India: I-Fossil fuel combustion. Atmos. Environ. 36, 677-697, doi:10.1016/S1352-2310(01)00463-0 (2002).

Kupiainen, K. \& Klimont, Z. Primary emissions of fine carbonaceous particles in Europe. Atmos. Environ. 41, 2156-2170, doi:10.1016/j.atmosenv.2006.10.066 (2007).

95 Aasestad, K. Emissions of black carbon and organic carbon in Norway 1990-2011. 65 (Statistisk sentralbyrå, Oslo, Norway, 2013).

Fry, M. M. et al. The influence of ozone precursor emissions from four world regions on tropospheric composition and radiative climate forcing. Journal of Geophysical Research: Atmospheres 117, D07306, doi:10.1029/2011jd017134 (2012).

$\mathrm{Yu}, \mathrm{H}$. et al. A multimodel assessment of the influence of regional anthropogenic emission reductions on aerosol direct radiative forcing and the role of intercontinental transport. Journal of Geophysical Research: Atmospheres 118, 700-720, doi:10.1029/2012JD018148 (2013). Reisinger, A., Meinshausen, M., Manning, M. \& Bodeker, G. Uncertainties of global warming metrics: $\mathrm{CO}_{2}$ and $\mathrm{CH}_{4}$. Geophys. Res. Lett. 37, L14707, doi:10.1029/2010gl043803 (2010).

99 Boucher, O., Friedlingstein, P., Collins, B. \& Shine, K. P. The indirect global warming potential and global temperature change potential due to methane oxidation. Environ. Res. Lett. 4, 044007, doi:10.1088/17489326/4/4/044007 (2009).

Gillett, N. P. \& Matthews, H. D. Accounting for carbon cycle feedbacks in a comparison of the global warming effects of greenhouse gases. Environ. Res. Lett. 5, 034011, doi:10.1088/1748-9326/5/3/034011 (2010). 
629

630

631

632

633

\section{Additional information}

Supplementary information is available for this paper. Correspondence and requests for materials should be addressed to K.T.

\section{Acknowledgments}

This research was partially supported by the Environment Research and Technology Development Fund (2-1702) of the Environmental Restoration and Conservation Agency, Japan. K.T. was supported by a Senior Fellowship at the Institute for Advanced Sustainability Studies, Potsdam, Germany to conduct the early phases of this study. F.C. and W.J.C. acknowledge the support from the Research Council of Norway, project no. 244074 and 235548 , respectively. The authors are grateful for comments from Olivier Boucher and Angela McLean, which were useful to improve this study.

\section{Author contributions}

K.T. led the study. K.T. and F.C. designed the experiment. O.C. and F.C. derived the emission data. W.J.C computed the emission metrics. K.T. and O.C. calculated the climate impacts. O.C. performed the Monte Carlo analysis. K.T. generated all the figures and tables. K.T., O.C., W.J.C., and F.C. analyzed the results. K.T. drafted the manuscript, with inputs from O.C., W.J.C., and F.C.

\section{Competing interests}

The authors declare no competing financial interests. 
"Asserting the climate benefits of the coal-to-gas shift across temporal and spatial scales" Katsumasa Tanaka, Otávio Cavalett, William Collins, Francesco Cherubini Final version submitted to Nature Climate Change (1 March 2019)

\begin{tabular}{|c|c|c|c|c|c|c|c|c|c|}
\hline \multirow{2}{*}{\multicolumn{2}{|c|}{ OUR APPROACH }} & \multicolumn{8}{|c|}{ IMPACT TIME SCALES AND DESIGNATED EMISSION METRICS } \\
\hline & & Very & term & Ver & term & & & & \\
\hline \multicolumn{2}{|c|}{ PREVIOUS APPROACH } & \multicolumn{2}{|c|}{-} & \multicolumn{2}{|c|}{ Short-term } & \multicolumn{2}{|c|}{ Long-term } & \multicolumn{2}{|c|}{-} \\
\hline \multicolumn{2}{|c|}{ EMISSION METRIC } & & & \multicolumn{2}{|c|}{ GWP20 } & \multicolumn{2}{|c|}{ GWP100 } & \multicolumn{2}{|c|}{ GTP100 } \\
\hline \multicolumn{2}{|c|}{$\begin{array}{l}\text { MULTI-METRIC } \\
\text { MULTI-BASKEt }\end{array}$} & \multicolumn{8}{|c|}{ LOWER IMPACT FUEL (OR BREAK-EVEN $\mathrm{CH}_{4}$ LEAKAGE RATE) } \\
\hline \multirow{4}{*}{$\begin{array}{l}z \\
0 \\
\frac{0}{4} \\
0 \\
\frac{1}{2} \\
\frac{5}{2}\end{array}$} & China & $5 \%$ & $2 \%$ & $3 \%$ & Coal & $9 \%$ & Coal & Gas & Gas \\
\hline & Germany & Gas & $4 \%$ & $9 \%$ & $4 \%$ & Gas & $4 \%$ & Gas & Gas \\
\hline & United States & $6 \%$ & Coal & $5 \%$ & Coal & Gas & Coal & Gas & Gas \\
\hline & India & $6 \%$ & Coal & $5 \%$ & Coal & Gas & Coal & Gas & Gas \\
\hline
\end{tabular}

650

651 Table 1. Summary of the impact assessments for representative coal and natural gas power plants in China,

652 Germany, the United States, and India. The upper part of the table indicates the time scale of impacts and

653 associated emission metrics used to characterize the impacts in this study and previous studies $3,9,17,22,39,66$. The

654 lower part of the table indicates the type of fuel (i.e. coal or gas) estimated to have lower climate impacts, or the

655 break-even $\mathrm{CH}_{4}$ leakage rate (considered up to 9\%), above which the impacts of gas become larger than those of

656 coal. Results from the multi-metric approach ${ }^{23-25}$ employed in this study are shown on the left in each cell; those

657 from the multi-basket approach ${ }^{31-33}$ are on the right. Bold text indicates the results based on the method

658 recommended by UNEP-SETAC ${ }^{26}$ (i.e. the multi-metric approach using GWP100 and GTP100 to capture short- and long-term climate impacts, respectively). 
"Asserting the climate benefits of the coal-to-gas shift across temporal and spatial scales" Katsumasa Tanaka, Otávio Cavalett, William Collins, Francesco Cherubini Final version submitted to Nature Climate Change (1 March 2019)

Figure 1. Short- (left) and long- (right) term climate impacts of coal (top) and natural gas (bottom) power plants in two stages. Emissions from stages 1 and 2 (stage 1: extraction and transport of the fuel to the power plant; stage 2: fuel combustion at the power plant) are on the left and right of the split on each bar, respectively. $\mathrm{CN}$, DE, US, and IN stand for China, Germany, the United States, and India, respectively. GWP20, GWP100, GTP20, and GTP100 are the emission metrics used to quantify the corresponding climate impacts. Impacts based on the metrics recommend by UNEP-SETAC (i.e. GWP100 and GTP100) are shown in filled bars. The multi-metric approach is used. $\mathrm{CH}_{4}$ leakage rates from natural gas power plants are assumed to be the inventory-based estimates for each country (see Methods). Short- and long-term impacts are shown in $\mathrm{gCH} \mathrm{H}_{4} \mathrm{eq} / \mathrm{kWh}$ and $\mathrm{gCO}_{2} \mathrm{eq} / \mathrm{kWh}$, respectively (see Methods).

Figure 2. Short- (left) and long- (right) term climate impacts of coal (top) and natural gas (bottom) power plants in different GHGs and SLCPs. Black horizontal lines placed from the bars for $\mathrm{CO}_{2}$ emissions represent net non-CO emissions. The outer ends of black horizontal lines thus indicate total net emissions. Emissions from both stages are shown. $\mathrm{CH}_{4}$ leakage rates from natural gas power plants are assumed to be the inventory-based estimates for each country (see Methods). See caption for Figure 1.

Figure 3. Differences in the climate impacts between coal and natural gas power plants. $\mathrm{CH}_{4}$ leakage rates from natural gas power plants are varied from the inventory-based rates up to $9 \%$. Results are based on the multimetric approach and presented by countries. Short- and long-term impacts based on the metrics recommend by UNEP-SETAC (i.e. GWP100 and GTP100, respectively) are shown in solid lines and indicated in bold text in the legend. Emissions from both stages are shown. Positive estimates (grey zone) indicate that natural gas has smaller climate impacts than coal. Error bars are $2 \sigma$ ranges obtained from the Monte Carlo analysis sampling the uncertainties in emission data and emission metrics.

Figure 4. Very short-term climate impacts for different emission and impacts locations. Emissions from stages 1 and 2 are on the left and right of the split on each bar, respectively. GTP20 for global emissions (i.e. global-global metric), GTP20 for regional emissions (i.e. regional-global metric), and RTP20 (i.e. regional-regional metric) for different latitudinal bands are the emission metrics used to quantify climate impacts, which are expressed as 
"Asserting the climate benefits of the coal-to-gas shift across temporal and spatial scales" Katsumasa Tanaka, Otávio Cavalett, William Collins, Francesco Cherubini Final version submitted to Nature Climate Change (1 March 2019) bars in grey, black, and other colors, respectively. $\mathrm{CN}, \mathrm{DE}, \mathrm{US}$, and IN indicate the plant locations. $\mathrm{CH}_{4}$ leakage rates from natural gas power plants are assumed to be the inventory-based estimates for each country. 
a) Coal, short

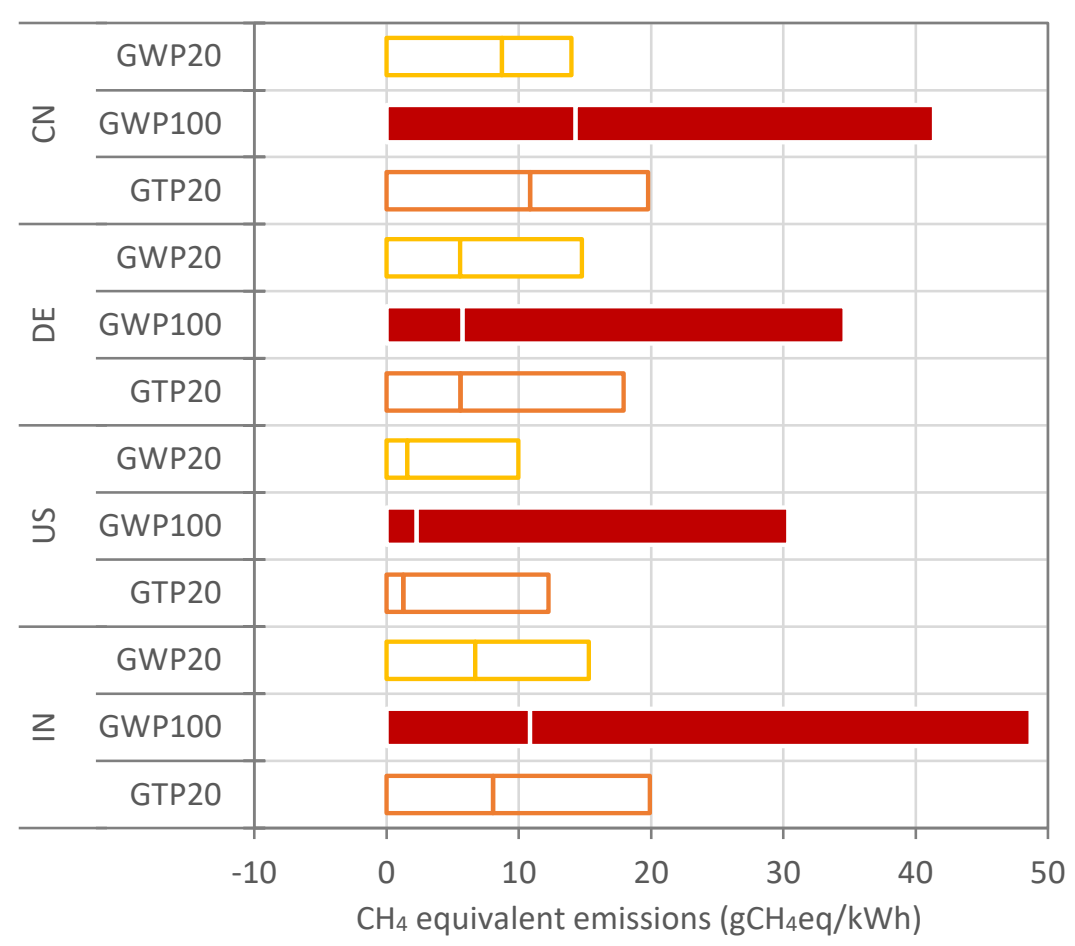

c) Gas, short

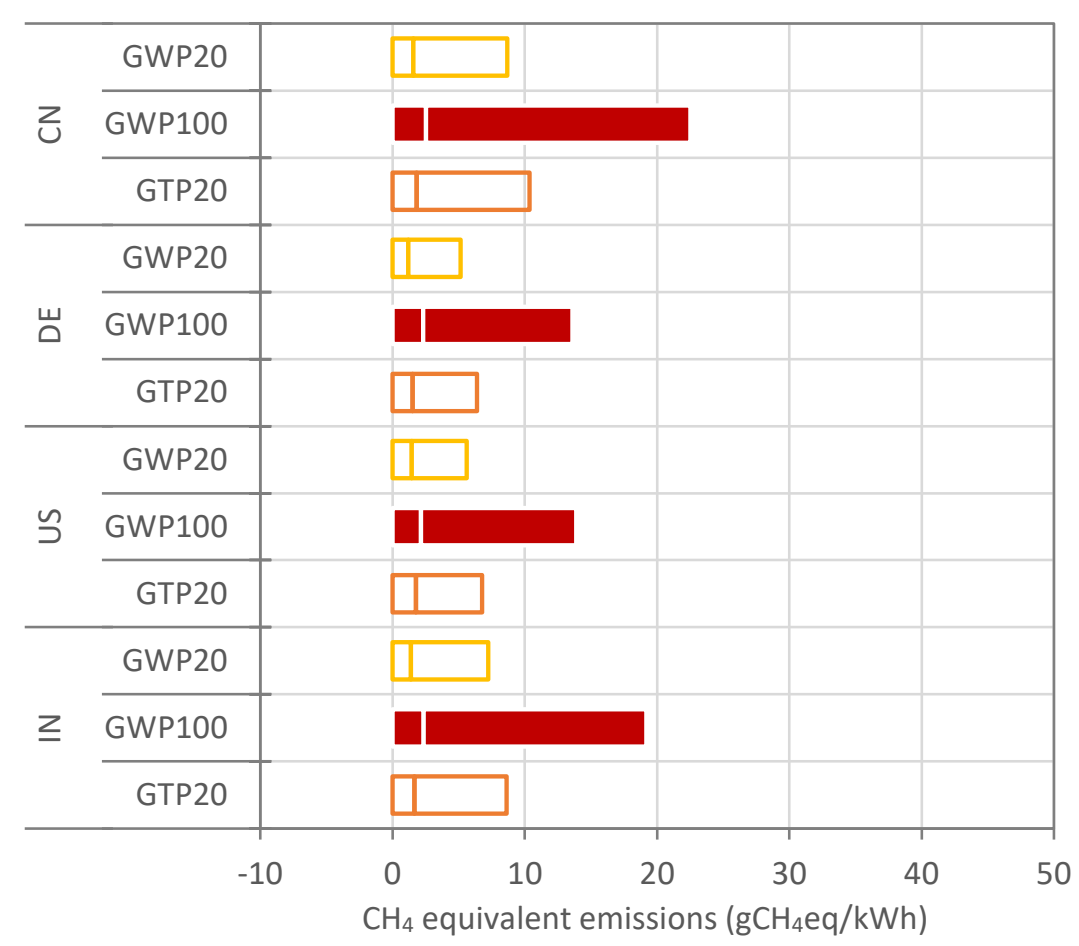

b) Coal, long

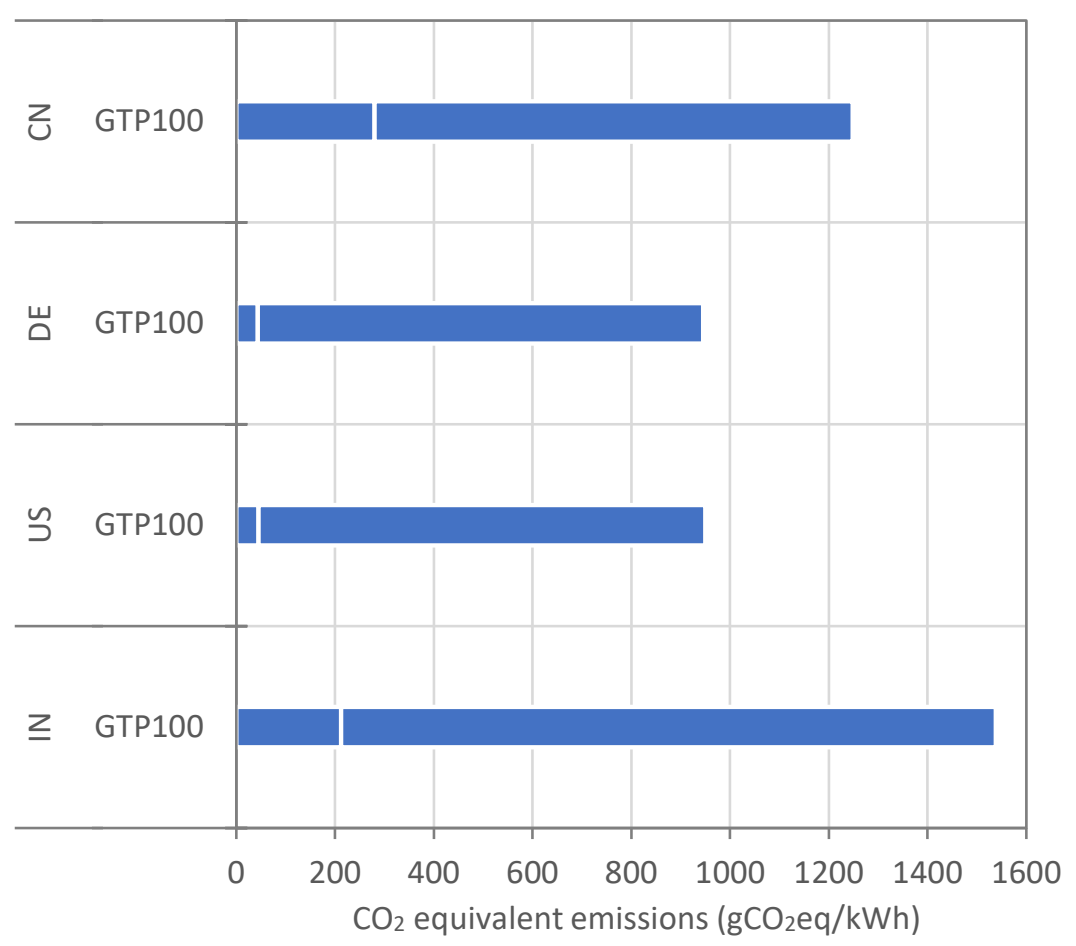

d) Gas, long

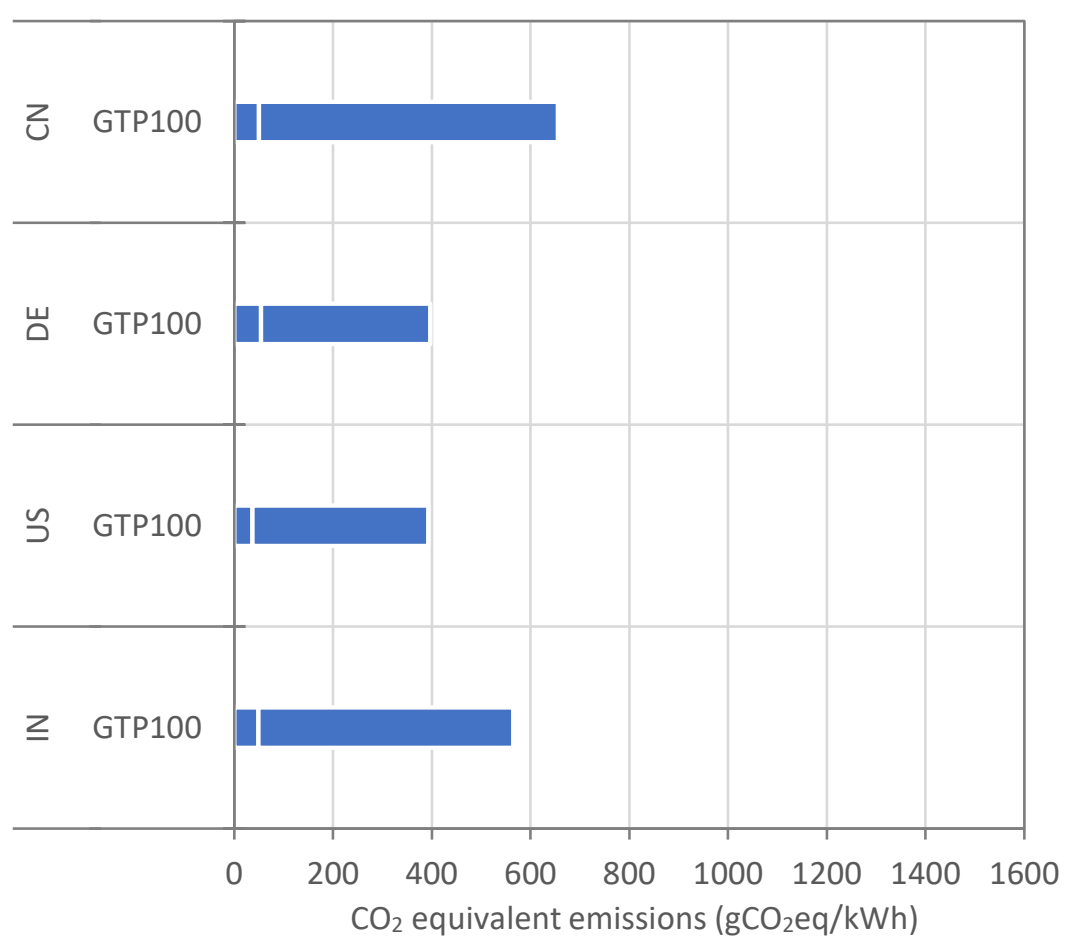


a) Coal, short

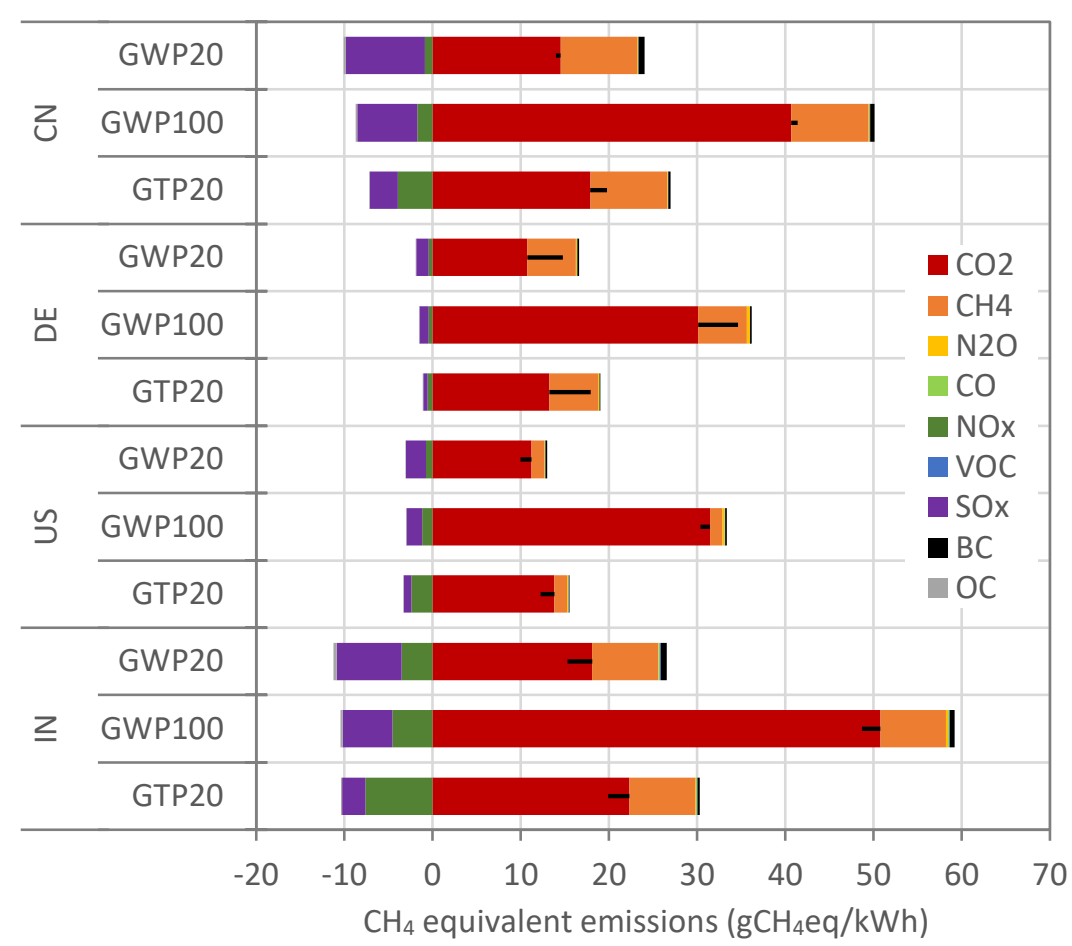

c) Gas, short

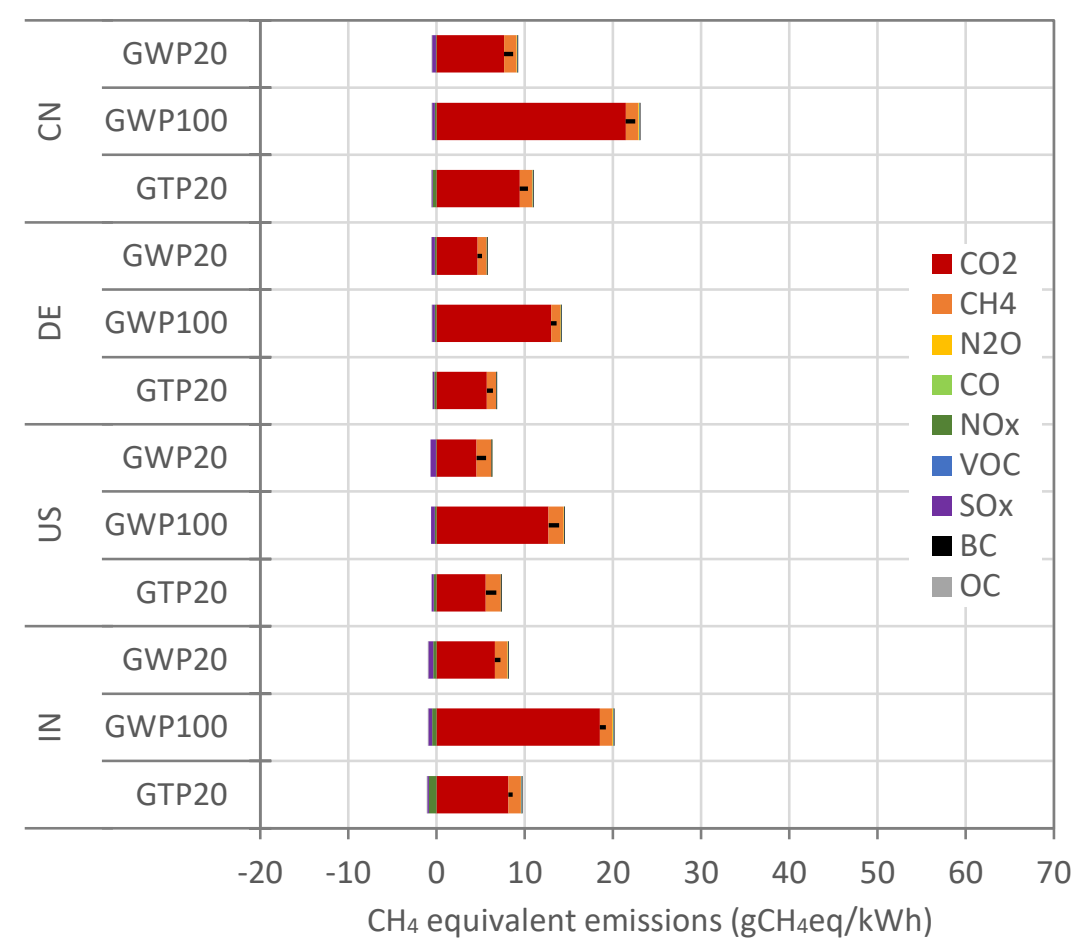

b) Coal, long

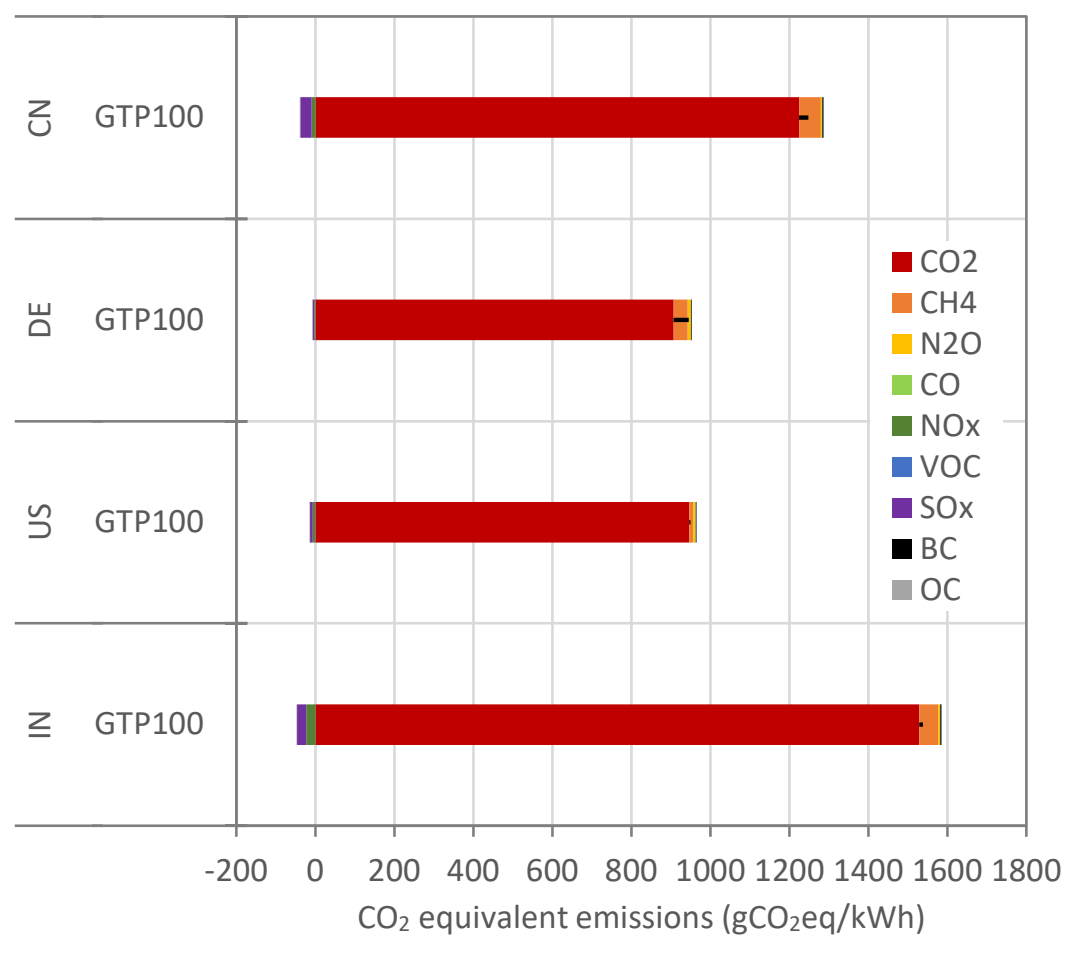

d) Gas, long

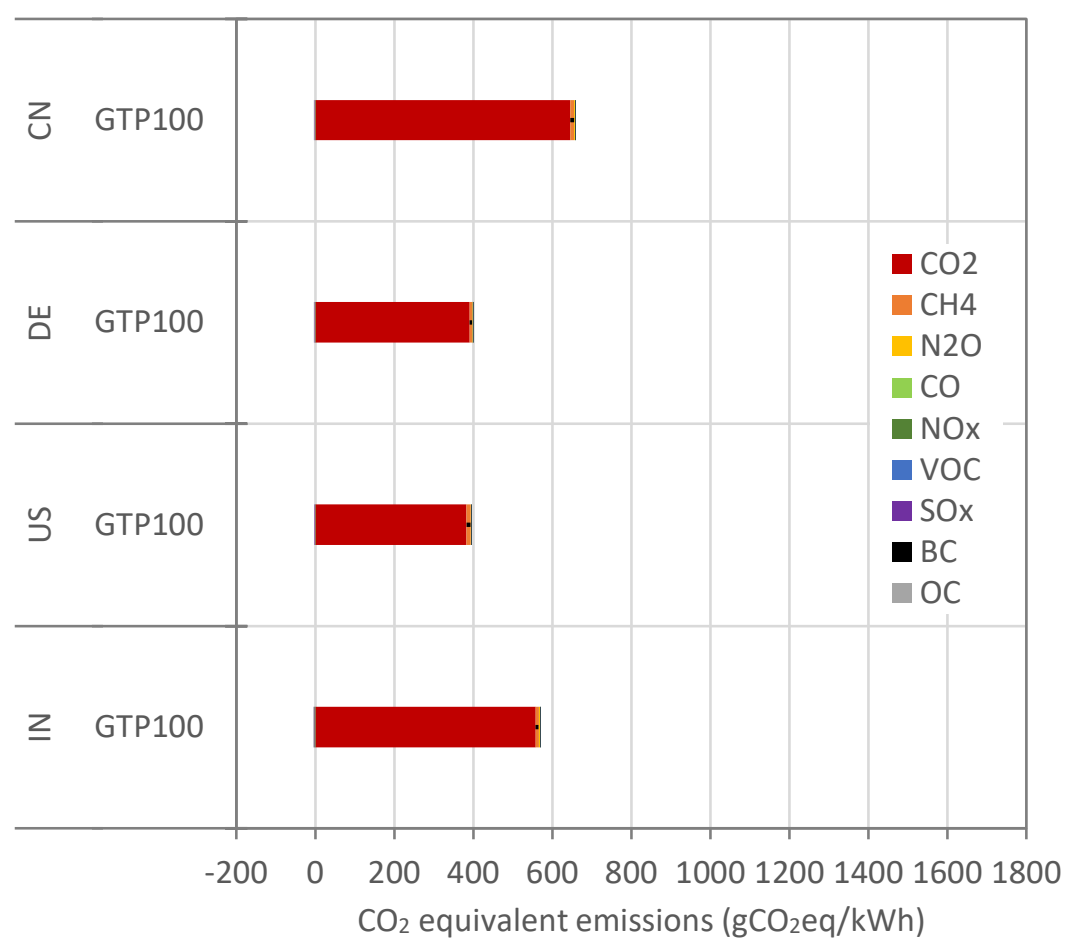


a) China

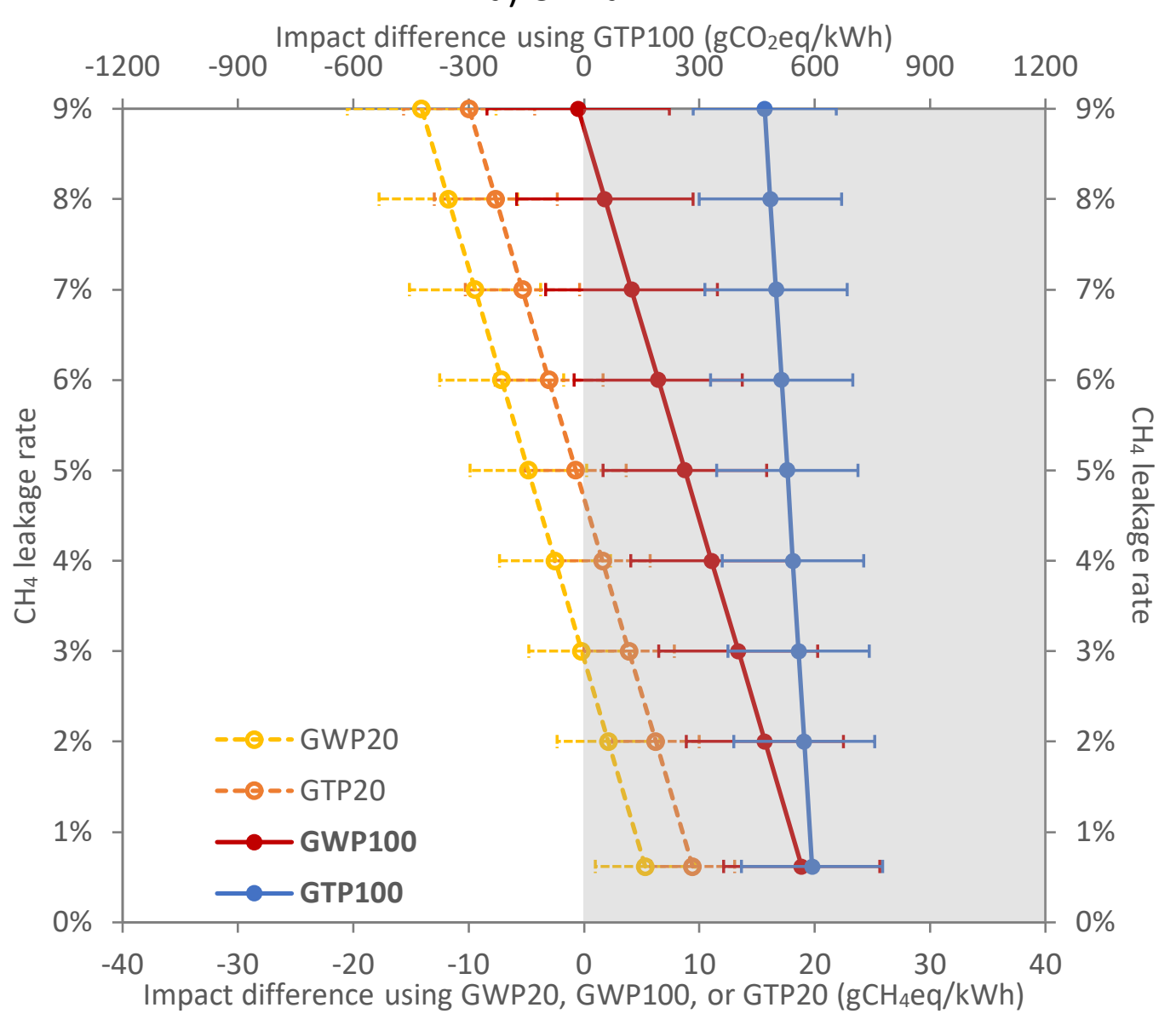

c) United States

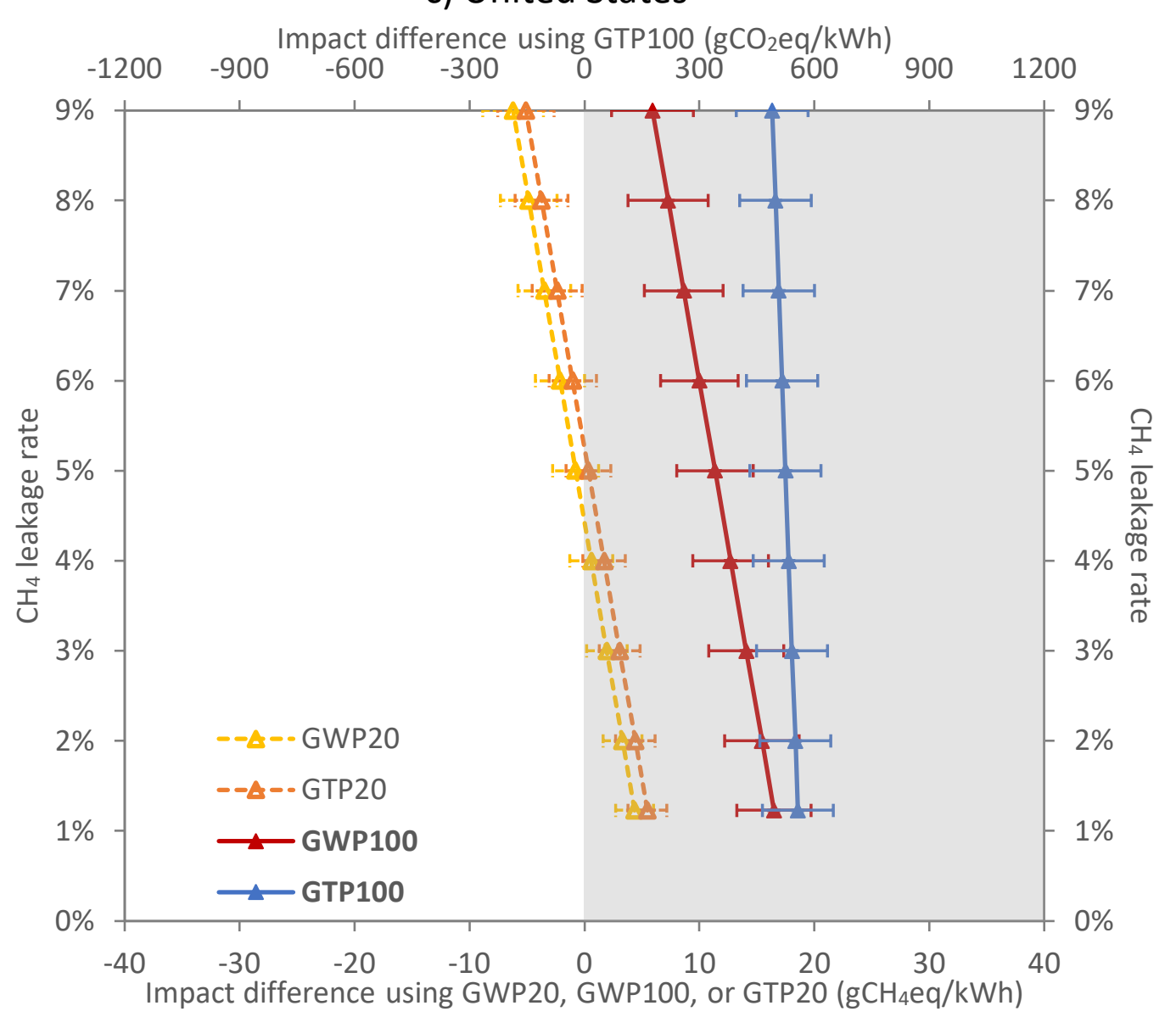

b) Germany

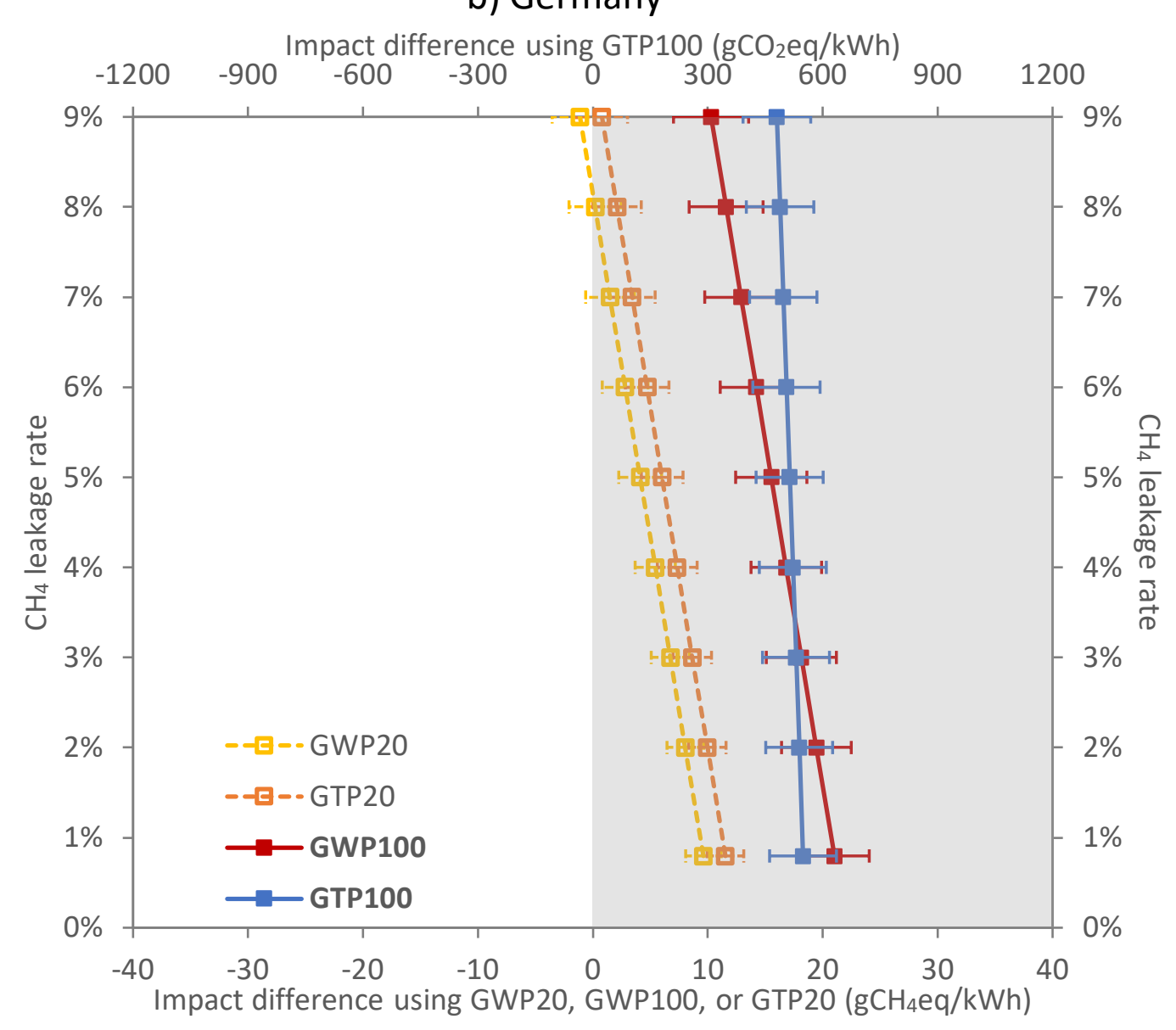

d) India

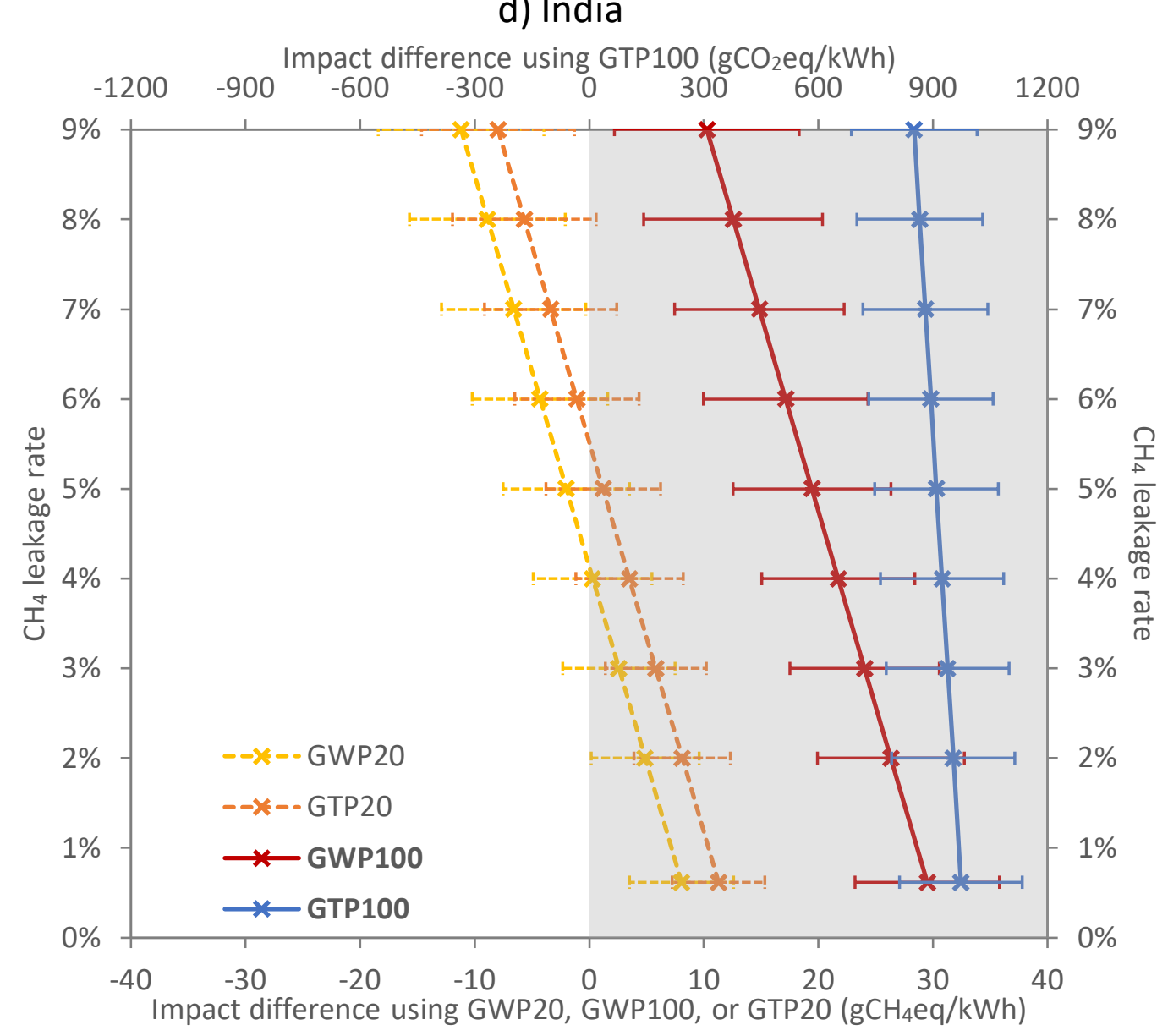


a) Coal

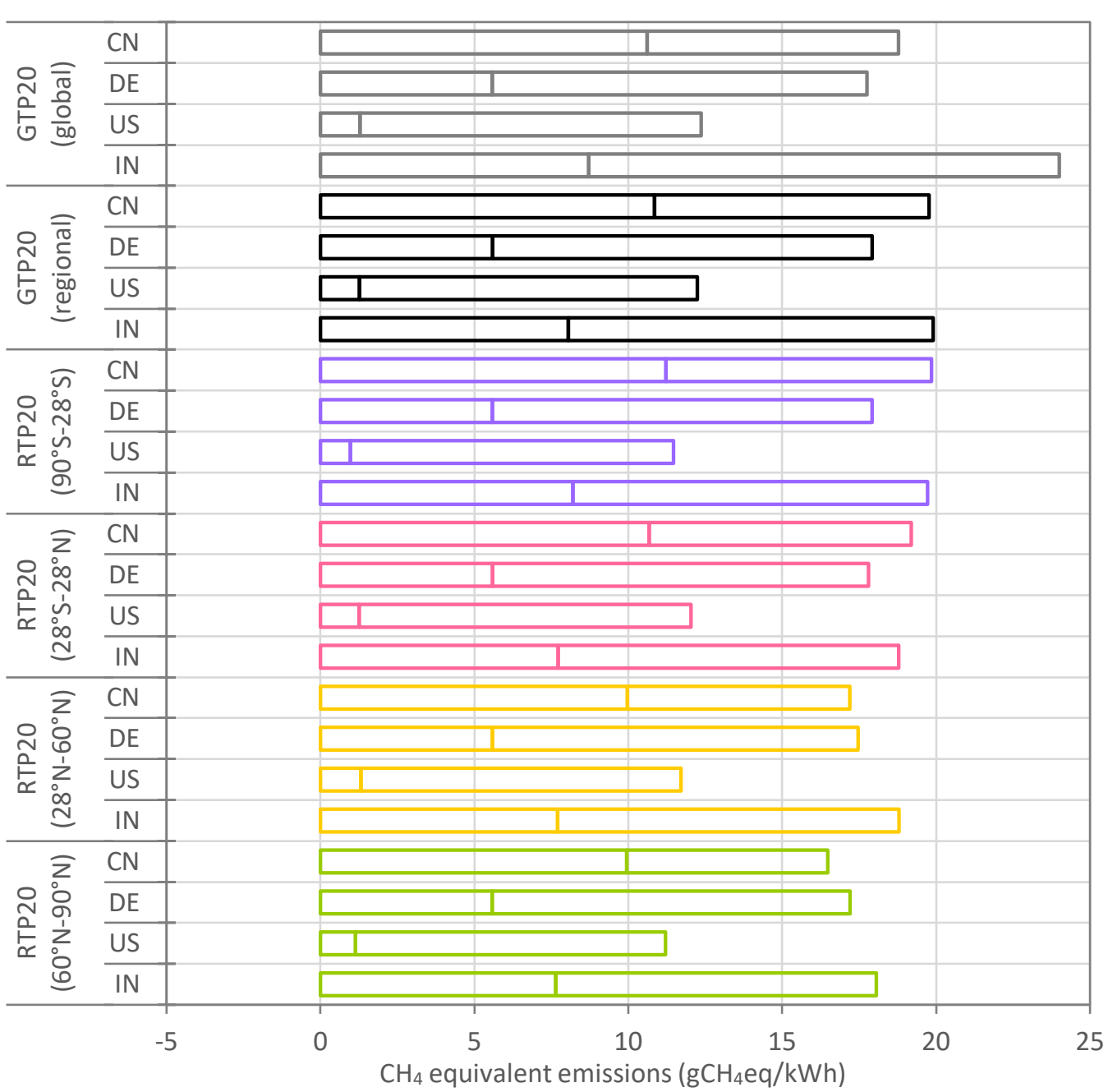

b) Gas

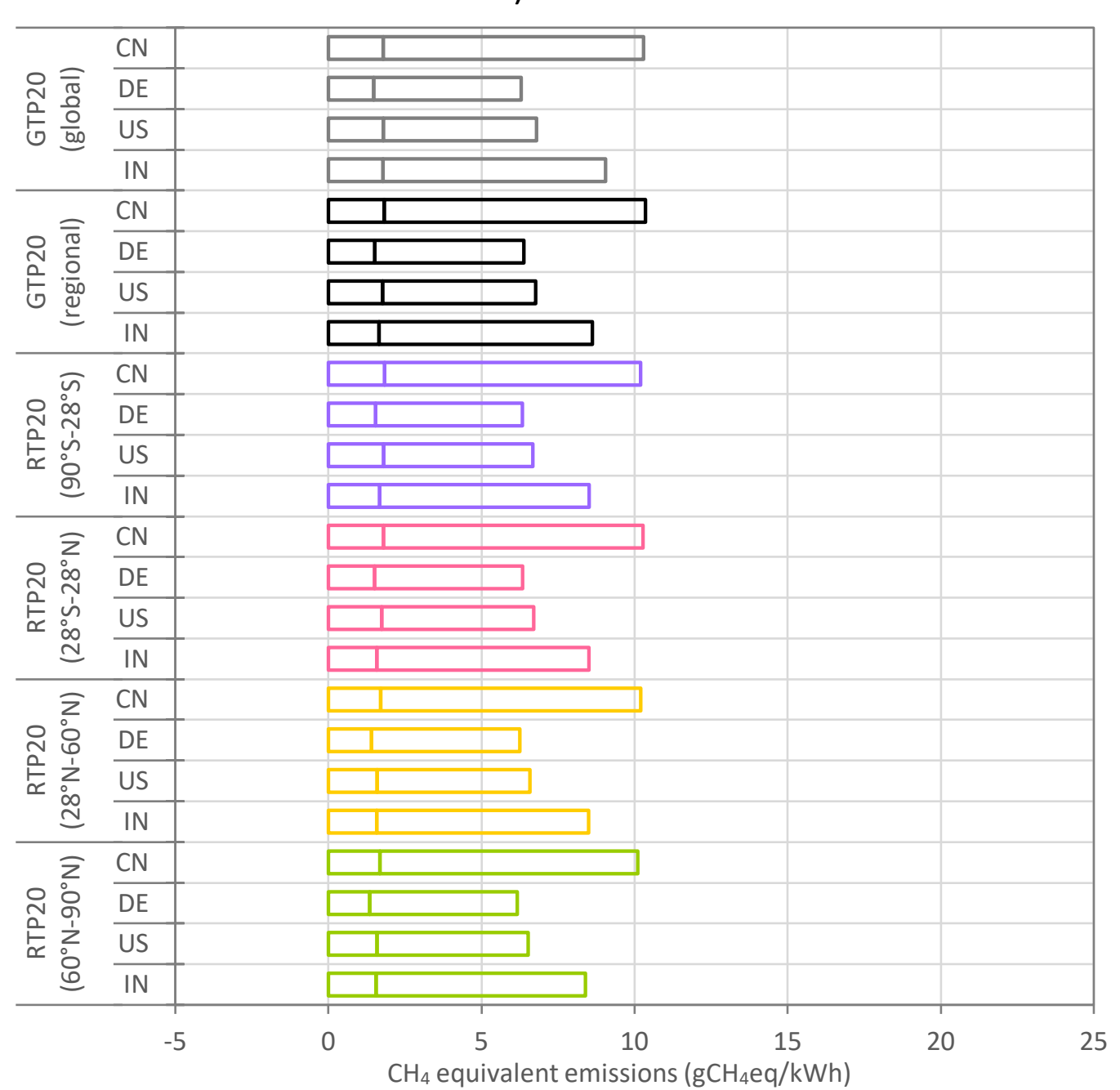

